\title{
Verbal intelligence is a more robust cross-sectional measure of cognitive reserve than level of education in healthy older adults
}

\section{Rory Boyle}

Trinity College Dublin: Trinity College Institute of Neuroscience https://orcid.org/0000-0003-0787-6892

\section{Silvin P Knight}

Trinity College Dublin: The University of Dublin Trinity College

\section{Céline De Looze}

Trinity College: The University of Dublin Trinity College

\section{Daniel Carey}

Trinity College: The University of Dublin Trinity College

\section{Siobhan Scarlett}

Trinity College: The University of Dublin Trinity College

\section{Yaakov Stern}

Columbia University Department of Neurology

\section{lan H Robertson}

Trinity College Dublin: The University of Dublin Trinity College

\section{Rose Anne Kenny}

Trinity College Dublin: The University of Dublin Trinity College

Robert Whelan ( $\nabla$ robert.whelan@tcd.ie)

https://orcid.org/0000-0002-2790-7281

\section{Research}

Keywords: Cognitive reserve, Cognitive ageing, Cognitive decline, Neuroimaging, Structural MRI

Posted Date: July 14th, 2021

DOI: https://doi.org/10.21203/rs.3.rs-216364/v2

License: (c) (1) This work is licensed under a Creative Commons Attribution 4.0 International License. Read Full License

Version of Record: A version of this preprint was published at Alzheimer's Research and Therapy on July 12th, 2021. See the published version at https://doi.org/10.1186/s13195-021-00870-z. 


\section{Abstract}

\section{Background}

Cognitive reserve is most commonly measured using socio-behavioural proxy variables. These variables are easy to collect, have a straightforward interpretation, and are widely associated with reduced risk of dementia and cognitive decline in epidemiological studies. However, the specific proxies vary across studies and have rarely been assessed in complete models of cognitive reserve (i.e., alongside both a measure of cognitive outcome and a measure of brain structure). Complete models can test independent associations between proxies and cognitive function in addition to the moderation effect of proxies on the brain-cognition relationship. Consequently, there is insufficient empirical evidence guiding the choice of proxy measures of cognitive reserve and poor comparability across studies.

Method

In a cross-sectional study, we assessed the validity of 5 common proxies (education, occupational complexity, verbal intelligence, leisure activities, and exercise) and all possible combinations of these proxies in 2 separate community-dwelling older adult cohorts: The Irish Longitudinal Study on Ageing (TILDA; $N=313$, mean age $=68.9$ years, range $=54-88$ ) and the Cognitive Reserve/ Reference Ability Neural Network Study (CR/RANN; $N=234$, mean age $=64.49$ years, range $=50-80) .15$ models were created with 3 brain structure variables (grey matter volume, hippocampal volume, and mean cortical thickness) and 5 cognitive variables (verbal fluency, processing speed, executive function, episodic memory, and global cognition).

Results

No moderation effects were observed. There were robust positive associations with cognitive function, independent of brain structure, for 2 individual proxies (verbal intelligence and education), and 16 composites (i.e., combinations of proxies). Verbal intelligence was statistically significant in all models. Education was significant only in models with executive function as the cognitive outcome variable. Three robust composites were observed in more than two thirds of brain-cognition models: the composites of 1) occupational complexity and verbal intelligence, 2) education and verbal intelligence, and 3) education, occupational complexity and verbal intelligence. However, no composite had larger average effects nor was more robust than verbal intelligence alone.

Conclusion

These results support the use of verbal intelligence as a proxy measure of CR in cross-sectional studies of cognitively healthy older adults.

\section{Background}


Neuropathology and measures of brain structure do not fully explain cognitive decline (1) nor age-related variation in cognitive function (2). This is evident in the finding of normal cognitive function in individuals who meet the diagnostic criteria for Alzheimer's disease (AD) based on neuropathology $(3,4)$. This wellestablished gap between brain and cognition may be explained by cognitive reserve (CR), wherein the effects of brain pathology or ageing on cognitive function are moderated by an individual's ability to efficiently or flexibly use the brain's resources to cope with task demands (5).

Accurate measurement of $\mathrm{CR}$ could improve the detection of, and risk assessments for, age-related cognitive decline and $A D(6)$ and improve the measurement of intervention efficacy in clinical trials and intervention studies by enabling researchers to effectively statistically control for CR (7). Difficulties in measuring CR (8), however, limit this potential. The most direct measures of CR are likely to be obtained using functional neuroimaging (8). CR may be measured with functional MRI using resting-state and task-based functional connectivity. For example, a pattern of greater change in functional connectivity from resting state in response to task demands is associated with better cognitive performance, above and beyond the effects of cortical thickness (9). However, the considerable cost of MRI scanning (10) limits access to such measures, particularly in lower income countries (11). As such, socio-behavioural variables reflecting the degree of exposure to, or engagement in, various lifetime experiences are often used as proxies of $\mathrm{CR}(8)$.

The rationale for using proxies is that greater exposure to certain lifetime experiences increases the adaptability of cognitive and functional brain processes, thereby enabling a greater ability to cope with brain changes or damage (8). Considerable epidemiological evidence indicates a reduced risk and/or delayed onset of dementia and cognitive decline in individuals with greater educational attainment (1214); occupational complexity/status (15-17); literacy and/or verbal intelligence (18-21); engagement in activities that were cognitively stimulating $(22,23)$; leisure-related $(24,25)$; physical $(22,26-28)$; and social $(22,23,29)$. Proxies also provide a single value with a simple interpretation - a higher degree of exposure reflects greater $\mathrm{CR}$. Moreover, proxies are easy and inexpensive to obtain, and some, such as educational attainment, are routinely collected as part of most ageing studies. It is therefore not surprising that CR is most often measured using proxies (30).

Despite their advantages, the use of proxies to measure CR has been criticised. First, some proxies, such as educational attainment, are typically static measures (31) despite the fact that CR is considered to be a dynamic construct that can change over time (32). Second, some argue that a single proxy fails to reflect the full $C R$ construct which is thought to be influenced by a range of experiences $(33,34)$. Finally, proxies may also be associated with cognitive decline via mechanisms other than reserve (35). For instance, greater educational attainment is correlated with higher socioeconomic status (36) which is itself associated with slower cognitive decline (37) and reduced risk and prevalence of dementia $(38,39)$. Low socioeconomic status is associated with various other factors, including stress and access to healthcare, which could exacerbate cognitive decline (38). As such, the protective effect of education on cognitive decline and dementia (but cf. 40 for an alternative perspective) may be via mechanisms related to socioeconomic status, rather than $\mathrm{CR}(41)$. 
The limitations of individual proxies may be mitigated by averaging (cf. transformation methods such as principal component analysis) multiple proxies to create a composite proxy measure that still provides a single summary value with a simple interpretation (42-46). Composite proxies allow for a wider range of contributions to $\mathrm{CR}$ and enable the inclusion of dynamic proxies that can change over time, such as verbal intelligence or engagement in activities (31). Furthermore, composite proxies may attenuate the issue of non-CR mechanisms of individual proxies because alternative mechanisms (e.g., socioeconomic status) might only be associated with some proxies, such as educational attainment, but not others like social engagement. Some composite-type approaches, including factor analytic and latent variable models, measure CR using inappropriate reflective measurement models, where the observed CR proxies are effectively considered to be reflective (i.e., caused by) the latent CR construct (35). Composite proxies are a more appropriate formative measurement model, where the observed proxies are considered to form, or cause, CR. Moreover, this approach can reflect the unique additive contributions of individual proxies, whereas factor analytic models reflect only the shared variance across different proxies (8).

While the composite approach offers advantages over the use of single proxies, there is no agreed-upon gold-standard composite proxy (30) just as there is likewise no gold-standard individual proxy. Similarly, it is unclear which proxy should be used when assessing candidate neuroimaging measures of $C R$, as face validity is assessed via their association with CR proxies $(47,48)$. The considerable variation $(49,50)$ and lack of coherence in the use of proxies means that there is poor comparability across studies, as an effect observed for one proxy (e.g., educational attainment), may not be observed to the same degree for another (e.g., occupational complexity), even though both putatively reflect CR. It also provides researchers in the field of CR with an additional "researcher degrees of freedom" (51) such that several different proxies could be examined but only statistically significant results are reported.

To assess the validity of a potential measure of $C R$, a complete model of $C R$ is required, which includes 3 components: a measure of CR (e.g., a proxy), a measure of brain structure/pathology, and a measure of cognitive function $(8,52)$. This enables the assessment of the cognitive benefit criterion (48). This criterion can be satisfied via the observation of 1) an "independent effect" in which the candidate measure is positively associated with cognitive function, independent of brain structure, or 2) a "moderation effect" in which the candidate measure moderates the relationship between brain structure and cognitive function $(8,47)$. The moderation effect is considered the ideal benchmark for $C R$, whereas the independent effect is considered a weaker level of evidence for a CR effect (8).

A systematic review of $\mathrm{CR}$ proxies from complete $\mathrm{CR}$ models reported inconclusive evidence for educational attainment, occupational complexity/status and leisure activity as proxies of CR in cognitively healthy cohorts (53). A single reviewed study provided evidence that greater engagement in cognitively stimulating activities in mid- and late-life provided CR effects (54). Other proxies were not assessed in this systematic review, although individual studies have reported positive evidence for $\mathrm{CR}$ effects in complete CR models. Verbal intelligence has been positively associated with cognition, controlling for global AD neuropathology or hippocampal atrophy in cognitively healthy $(55,56)$ and cognitively impaired older adults (55). Physical activity was positively associated with cognition in the 
presence of neuropathology (57) but not hippocampal atrophy (56). Social engagement moderated the relationship between amyloid-beta deposition and cognitive decline (58). The composite of verbal intelligence and education moderated the relationship of subcortical grey matter (GM) volume and cortical thickness with fluid reasoning but not memory or processing speed and attention (46). This composite was also associated with memory controlling for GM volume (59) and global cognition controlling for a composite AD-biomarker (45). Although other composites have been associated with cognition (50), there is very little empirical evidence regarding their effects within complete CR models.

There is currently no conclusive evidence for the best individual or composite proxy for measuring or validating neuroimaging measures of $\mathrm{CR}$, particularly with respect to cognitively healthy older adults. $\mathrm{A}$ methodology for solving this problem is the use of hierarchical linear moderated regressions to systematically assess standard CR proxies and their composites in complete models, an approach that enables the examination of both moderation and independent effects within the same analysis framework. This is important because, although moderation effects should ideally be observed to validate a CR proxy or measure (8), they are typically small in real-world data (60), explaining $1-3 \%$ of the variance in the outcome (61). Consequently, large sample sizes are required to detect typically small moderation effects (62). This issue is further exacerbated when measurement error is present in either variable in the interaction term (e.g., the CR proxy and measure of brain structure) used to assess the moderation effect (63) or when either variable in the interaction term is associated with the outcome variable (e.g., cognitive function; 65). Given the noted difficulties in identifying moderation effects, it is important to also consider the independent effect when assessing the validity of CR proxies.

Hierarchical linear regressions allow the robustness (i.e., frequency of effects using different measures of brain structure and cognitive function) and magnitude of both moderation and independent effects of different proxies to be compared. Here, in two separate community-dwelling older adult cohorts, we examined five common putative CR proxies - education, occupational complexity, verbal intelligence, leisure activities, and exercise - and all of their possible combinations. We included three brain structure variables, mean cortical thickness, hippocampal volume, and grey matter volume, in each model. Our primary aim was to identify the $\mathrm{CR}$ proxies with the most robust and largest effects across two datasets. More formally, we define effective CR proxies as those variables that have a significant independent or moderation effect on measures of cognitive function and brain structure.

\section{Method}

\section{Participants}

The first dataset consisted of data from 313 community-dwelling adults (mean age $=68.90$ years, SD $=$ 6.75 years, range $=54-88$ years; $50.48 \%$ female), a subset of The Irish Longitudinal Study on Ageing (TILDA), a nationally representative longitudinal cohort study of older adults in Ireland $(64,65)$. This data was collected during Wave 3 of the TILDA study (66). All participants were screened for MRI 
contraindications and study-specific inclusion criteria included: no history of neurological conditions and available data for $\mathrm{CR}$ proxies and cognitive function.

The second dataset consisted of data from 234 community-dwelling adults (mean age $=64.49$ years, SD $=7.42$ years, range $=50-80$ years; $51.28 \%$ female) selected from participants in the Cognitive Reserve/Reference Ability Neural Network (CR/RANN) studies (67-69). Participants were screened for MRI contraindications, hearing and visual impairments, medical or psychiatric conditions, and dementia or $\mathrm{MCl}$. Participants selected for the current analyses were aged 50 years or older with data available for CR proxies, cognitive function and MRI.

\section{Measures: CR Proxies}

Data was available for 5 socio-behavioural proxies in both datasets: Educational attainment, Occupational complexity, Verbal intelligence, Leisure activities, and Physical activity. In TILDA, further data was available for the proxies: Cognitively stimulating activities and Social engagement.

Educational attainment was measured using years of formal education in both datasets. In TILDA, participants were asked to indicate the age at which they first left continuous full-time education. This information was missing for 4 participants in the final sample (1.28\%), so it was imputed using educational qualification, father's education, age, sex, and rural residence during childhood as previously described (70).

Occupational complexity was measured using the complexity of work in the dimensions of data, people, and things (71) using ratings obtained from an online catalogue of the Dictionary of Occupational Tiles (DOT: www.occupationalinfo.org). Ratings for each dimension were reversed (such that higher scores reflected greater complexity) and then summed to create a total occupational complexity score, with scores ranging from 0 (minimal complexity) to 21 (maximal complexity). This was obtained for each participant's current occupation or last occupation before retirement in TILDA and for participant's occupation of longest duration of their lifetime in CR/RANN.

Verbal intelligence was measured using the total number of correctly pronounced words on the National Adult Reading Test (NART; Nelson \& Willinson, 1982) in TILDA and the American National Adult Reading Test (AMNART; Grober \& Sliwinski, 1991) in CR/RANN. In TILDA, a stress/anxiety-preventative and timesaving measure (75) was employed such that participants only completed the second half of the NART if they scored greater than 20 on the first half. A correction procedure was employed whereby scores of $0-$ 11 were retained as full scores, but scores of 12-20 in participants who did not complete the second half were corrected using a conversion table outlined by Beardsall and Brayne (76) (77). Possible scores on the NART, in TILDA, ranged from 0 to 50 and on the AMNART, in CR/RANN, from 0 to 45. While the NART is often used to provide a measure of premorbid intelligence, we have labelled NART scores here as verbal intelligence in line with previous cognitive reserve studies $(42,78)$. The NART is "effectively a test of knowledge acquisition" (79) that may reflect the exposure to various educational and cognitive experiences across the lifespan (80-83). 
Leisure activities were assessed in TILDA by participants rating their current frequency of engagement on an 8-point Likert scale ( $0=$ Never to $7=$ Daily/Almost Daily) in 9 activities: watching television, going to films/plays/concerts, travel, listening to music/radio, going to the pub, eating out, sports/exercise, visiting/talking on phone, and volunteering. In CR/RANN, participants rated their frequency of engagement over the preceding 6 months on a 3-point Likert scale ( $1=$ Never to $3=0$ Often $)$ in 17 activities: television/radio, cards/games, reading, lectures/concerts, theatre/movies, travel, walks/rides, crafts/hobbies, music, visiting, sports/dancing/exercise, cooking, group membership, collecting, religious activities, and volunteering. For both datasets, total scores were created by summing individual responses and possible scores ranged from 17 to 51 .

Physical activity was assessed in TILDA by calculating the total metabolic minutes arising from selfreported physical activity over the last week using the International Physical Activity Questionnaire-Short Form (IPAQ-SF; Craig et al., 2003; Lee et al., 2011). This questionnaire assessed the time spent in 3 categories: vigorous, moderate, and walking. Responses were converted to metabolic equivalent minutes (84) and summed. In CR/RANN, physical activity was calculated using total metabolic hours arising from physical activity in an average week. The Godin leisure time exercise questionnaire (86) assessed the frequency of activity sessions lasting $>15$ mins in 3 categories: strenuous, moderate, and mild exercise. Responses were then weighted by the average estimated duration of activity in each category $(0.5,0.75,1$ hr respectively) and their metabolic equivalent values (9, 5, 3; Ogino et al., 2019; Scarmeas et al., 2009).

Cognitively stimulating activities were assessed in TILDA with a questionnaire where participants rated their frequency of engagement on an 8-point Likert scale $(0=$ Never to $7=$ Daily/Almost Daily $)$ in 5 activities: attending classes and lectures, working in the garden/home or on a car, reading books/magazines, spending time on hobbies/creative activities, and playing cards/bingo/games. Total scores were created by summing individual responses and possible scores ranged from 0 to 35 .

Social engagement was measured in TILDA using the Social Network Index (88) which provides a total score, ranging from 0 to 4 , reflecting an individual's degree of social connection (89).

Composite proxies were created by first standardising (z-scoring) individual proxies. Next, every unique combination of proxies was generated and the composite proxy was the average of those proxies. For TILDA, this produced 120 unique composite proxies. For CR/RANN, this resulted in 26 composite proxies.

To summarize, for TILDA there were 127 proxies in total (individual and composite) and 31 in total for CR/RANN. To attenuate possible effects of outliers, all proxies were Winsorized using a robust technique based on the median absolute deviation (90). Outliers were identified as values greater than a threshold of 3 median absolute deviations from the median. Identified outliers were replaced by the median $+/-3$ median absolute deviations.

\section{Measures: Cognitive Function}

Verbal fluency was assessed using the total score on the Animal Naming Test which measures the ability to spontaneously produce the name of animals in one minute (75). The total number of animals named 
was used as the total score in both datasets.

Processing speed was measured using the time to complete the Colour Trails Task 1 (CTT 1; D'Elia et al., 1996) in TILDA and the Trail Making Task A (TMT A; Reitan, 1955) in CR/RANN. The CTT is considered a cross-culturally valid form of the TMT (75). Scores were reversed coded, such that higher scores reflected greater cognitive performance.

Executive function was assessed using the CTT 2 (D'Elia et al., 1996) in TILDA and the TMT B (Reitan, $1955)$ in CR/RANN. Both measures reflect the multi-dimensional executive function construct $(93,94)$, specifically visual attention and cognitive flexibility with contributions from processing speed as well (75). The time taken to complete both tasks was used as the outcome measure. Scores were reverse coded such that higher scores reflected greater cognitive performance.

Episodic memory was measured in both datasets with a composite measure created using the average of standardized and Winsorized immediate and delayed recall variables. In TILDA, immediate and delayed recall were measured using a 10-item word list (95) as used originally in the Health and Retirement Study (96). The word list was assessed over 2 trials in TILDA and the average score for immediate and delayed recall from both trials were used. In CR/RANN, immediate and delayed recall were measured using the total and delayed recall scores from the Selective Reminding Test (SRT; Buschke \& Fuld, 1974).

Global cognition was measured using a composite measure of all 5 cognitive variables in each dataset: verbal fluency, processing speed, executive function, episodic memory (immediate recall), and episodic memory (delayed recall). Cognitive variables were Winsorized and standardised prior to creation of the composite. The composite variable was then Winsorized and standardised itself.

\section{Measures: Brain Structure}

T1-weighted 3D magnetization-prepared rapid gradient echo (MPRAGE) scans were acquired in both datasets using a 3T scanner (Achieva, Philips Medical Systems, The Netherlands). TILDA parameters: $\mathrm{FOV}=240 * 240 * 162 \mathrm{~mm}^{3}$, matrix size $=288 * 288$, slice thickness $/$ gap $=0.9 / 0 \mathrm{~mm}, \mathrm{TR} / \mathrm{TE}=6.7 / 3.1 \mathrm{~ms}$. CR/RANN parameters: $\mathrm{FOV}=256 * 256 * 180 \mathrm{~mm}^{3}$, matrix size $=256 * 256$, slice thickness $/ \mathrm{gap}=1 / 0$ $\mathrm{mm}, \mathrm{TR} / \mathrm{TE}=6.5 / 3 \mathrm{~ms}$.

T1-MRIs were inspected and processed in TILDA and CR/RANN using FreeSurfer v6.0 and v5.1 (98), respectively, as described previously $(68,99)$. Total GM volume and hippocampal volume were obtained from Freesurfer and both were divided by Freesurfer's estimated total intracranial volume. Brain images were parcellated using the Desikan Killiany atlas, with 34 cortical regions of interest (ROIs) per hemisphere (100). The mean cortical thickness of each cortical ROI was calculated. Overall cortical thickness was calculated as the mean over cortical ROls. All variables were standardized and Winsorized (based on $z$-scores $>|3|$ ). These three measures were selected based on their availability across both datasets and because they have been used in previous studies, with complete CR models, to represent 
brain structure: GM volume $(101,102)$, hippocampal volume $(103,104)$, and mean cortical thickness $(9,43,105)$.

\section{Analysis}

Fifteen individual brain structure-cognitive function models were created for each combination of brain structure and cognitive function variable, where one brain structure variable was selected as an independent variable and one cognitive function variable was selected as an outcome variable (Fig. 1). A moderated hierarchical regression (Fig. 1) was conducted within each brain structure-cognitive function model $(n=15)$ for each unique proxy (TILDA = 127; CR/RANN = 31). In Step 1, a cognitive measure was regressed on age, sex, and a measure of brain structure. In Step 2, a proxy variable was included as an independent variable. In Step 3, the interaction term for brain structure and the proxy was added.

To protect against violations of linear regression assumptions, the analysis was repeated using a robust regression, specifically an iteratively reweighted least squares regression with Tukey's biweight function and median absolute deviation scaling. Significant effects within each dataset were only considered significant if they were statistically significant in both the linear regression and robust regression. To control for multiple comparisons and to ensure generalizability of findings, effects were only considered significant if they were statistically significant across both datasets. The analysis was conducted with customized Python code (available here: https://github.com/rorytboyle/hierarchical_regression) which

used the statsmodels module (106). The change in $\mathrm{R}^{2}$ (i.e. amount of variance explained) from Step 1 to Step 2, and from Step 2 to Step 3 in linear regression models were used to assess the size of the independent and moderation effects of CR proxies, respectively. Where significant effects were observed, the mean $\mathrm{R}^{2}$ change across both datasets was calculated to assess the average additional variance explained by the proxy and its interaction with brain structure.

[insert Fig. 1 here]

\section{Figure 1}

Schematic of basic brain structure-cognitive function models created for analysis.

\section{Results}

\section{Demographics}

In TILDA, some data were missing for mean cortical thickness $(\mathrm{N}=34)$ and CTT 2 and Global Cognition $(N=2)$. In $C R / R A N N$, the same $N$ was used $(N=234)$ in all models. Consequently, different Ns were used across models within TILDA (see Table 1). 
Table 1

Demographics for each hierarchical regression model

\begin{tabular}{|c|c|c|c|c|c|}
\hline Dataset & Brain Structure & Cognition & $\mathbf{N}$ & $\begin{array}{l}\text { Mean Age (SD, } \\
\text { Range) }\end{array}$ & $\begin{array}{l}\text { Sex } \\
(M / F)\end{array}$ \\
\hline \multirow[t]{10}{*}{ TILDA } & \multirow[t]{3}{*}{$\begin{array}{l}\text { Grey Matter Volume, Hippocampal } \\
\text { Volume }\end{array}$} & Verb Flu, & 313 & $\begin{array}{l}68.90(6.75,54- \\
88)\end{array}$ & $155 / 158$ \\
\hline & & $\begin{array}{l}\text { Proc } \\
\text { Speed, }\end{array}$ & & & \\
\hline & & Epi Mem & & & \\
\hline & \multirow[t]{2}{*}{$\begin{array}{l}\text { Grey Matter Volume, Hippocampal } \\
\text { Volume }\end{array}$} & $\begin{array}{l}\text { Exec } \\
\text { Func, }\end{array}$ & 311 & $\begin{array}{l}68.91(6.77,54- \\
88)\end{array}$ & $154 / 157$ \\
\hline & & Glob Cog & & & \\
\hline & \multirow[t]{3}{*}{ Mean Cortical Thickness } & Verb Flu, & 279 & $\begin{array}{l}69.16(6.64,54- \\
88)\end{array}$ & $137 / 142$ \\
\hline & & $\begin{array}{l}\text { Proc } \\
\text { Speed, }\end{array}$ & & & \\
\hline & & Epi Mem & & & \\
\hline & \multirow[t]{2}{*}{ Mean Cortical Thickness } & $\begin{array}{l}\text { Exec } \\
\text { Func, }\end{array}$ & 277 & $\begin{array}{l}69.18(6.66,54- \\
88)\end{array}$ & $136 / 141$ \\
\hline & & Glob Cog & & & \\
\hline CR/RANN & All & All & 234 & $\begin{array}{l}64.49(7.42,50- \\
80)\end{array}$ & $114 / 120$ \\
\hline
\end{tabular}

[insert Fig. 2 here]

Figure 2

Heatmaps showing Pearson's correlations between individual proxies in each dataset. $*=p<.05, * *=p$ $<.01, * * *=p<.001$.

\section{Step 1: Brain-Cognition Relationships}

Models in Step 1 of the hierarchical regression (i.e., containing a brain structure measure, sex, and age) were significantly associated with cognitive measures across both datasets (see Tables 2 and 3), except for two models in CR/RANN (hippocampal volume-executive function, and hippocampal volume-episodic memory). Sex was independently associated with cognitive function in $40 \%$ and $20 \%$ of brain-cognition models in TILDA and CR/RANN, respectively. In TILDA, females had higher cognitive function than males, on average, with other variables (i.e., brain structure and age) being equal. In CR/RANN, females had lower cognitive function than males, on average, with other variables being equal. Age was negatively 
associated with cognitive function, independent of brain structure and sex, in $100 \%$ and $40 \%$ of models in TILDA and CR/RANN, respectively.

In TILDA, only one brain structure variable, mean cortical thickness, was independently positively associated with cognitive function (processing speed). In CR/RANN, grey matter volume was independently positively associated with all cognitive measures and cortical thickness was independently positively associated with all cognitive measures except for processing speed. Hippocampal volume was not independently associated with any measure of cognition in either dataset.

Table 2

Step 1 of hierarchical regression models in TILDA.

\begin{tabular}{|c|c|c|c|c|c|c|c|}
\hline \multirow[t]{2}{*}{ Cognition } & \multicolumn{3}{|c|}{ Model Statistics } & \multicolumn{2}{|l|}{ Brain Structure } & \multirow{2}{*}{$\begin{array}{l}\text { Sex } \\
\beta\end{array}$} & \multirow{2}{*}{$\begin{array}{l}\text { Age } \\
\beta\end{array}$} \\
\hline & $\mathrm{n}$ & $\mathrm{R}^{2}$ & $f$ & Variable & $\beta$ & & \\
\hline Verb Flu & 313 & .043 & $4.597 \star \star$ & \multirow[t]{5}{*}{ Grey Matter Volume } & .042 & -.030 & $-.205^{\star \star}$ \\
\hline $\begin{array}{l}\text { Proc } \\
\text { Speed }\end{array}$ & 313 & .129 & 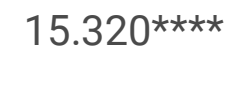 & & .041 & .084 & $-.360 * \star \star \star *$ \\
\hline Exec Func & 311 & .143 & 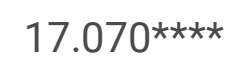 & & .048 & .052 & $-.383^{* * * *}$ \\
\hline Epi Mem & 313 & .079 & $8.780 * \star \star \star$ & & .021 & $.352^{\star \star}$ & $-.207^{\star \star}$ \\
\hline Glob Cog & 311 & .159 & 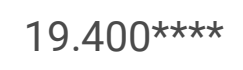 & & .048 & $.217^{\star}$ & $-.373^{\star \star * \star}$ \\
\hline Verb Flu & 313 & .042 & $4.475^{\star \star}$ & \multirow[t]{5}{*}{ Hippocampal Volume } & -.005 & -.004 & $-.229 \star \star$ \\
\hline $\begin{array}{l}\text { Proc } \\
\text { Speed }\end{array}$ & 313 & .129 & $15.226^{\star \star \star \star}$ & & -.025 & .120 & $-.394^{\star \star \star \star}$ \\
\hline Exec Func & 311 & .143 & 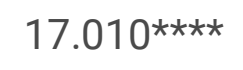 & & -.041 & .101 & $-.428^{\star \star \star \star}$ \\
\hline Epi Mem & 313 & .080 & $8.902^{\star \star \star \star}$ & & .044 & $.341^{\star \star}$ & $-.195^{\star \star}$ \\
\hline Glob Cog & 311 & .158 & $19.171^{\star \star \star \star}$ & & .002 & $.243^{\star}$ & 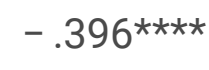 \\
\hline Verb Flu & 279 & .051 & $4.898 * \star$ & \multirow[t]{5}{*}{ Mean Cortical Thickness } & .103 & .002 & $-.192 \star \star$ \\
\hline $\begin{array}{l}\text { Proc } \\
\text { Speed }\end{array}$ & 279 & .173 & 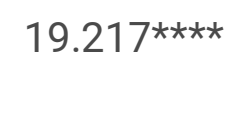 & & $.122 *$ & .042 & 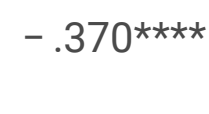 \\
\hline Exec Func & 277 & .195 & 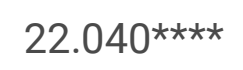 & & .090 & .065 & $-.428^{\star \star \star \star}$ \\
\hline Epi Mem & 279 & .091 & $9.202^{\star \star \star \star}$ & & -.036 & $.414^{\star \star}$ & $-.216^{\star \star \star}$ \\
\hline Glob Cog & 277 & .195 & $22.105^{\star \star \star \star}$ & & .065 & $.251^{*}$ & $-.391 * \star \star \star$ \\
\hline
\end{tabular}


Table 3

Step 1 of hierarchical regression models in CR/RANN.

\begin{tabular}{|c|c|c|c|c|c|c|c|}
\hline \multirow[t]{2}{*}{ Cognition } & \multicolumn{3}{|c|}{ Model Statistics } & \multicolumn{2}{|l|}{ Brain } & \multirow{2}{*}{$\begin{array}{l}\text { Sex } \\
\beta\end{array}$} & \multirow{2}{*}{$\begin{array}{l}\text { Age } \\
\beta\end{array}$} \\
\hline & $\mathrm{n}$ & $\mathrm{R}^{2}$ & $f$ & Variable & $\beta$ & & \\
\hline Verb Flu & 234 & .087 & $7.320 * \star \star$ & \multirow[t]{5}{*}{ Grey Matter Volume } & $.258 * \star \star$ & -.073 & -.062 \\
\hline $\begin{array}{l}\text { Proc } \\
\text { Speed }\end{array}$ & 234 & .087 & $7.344^{\star \star \star}$ & & $.218 * \star$ & $-.296^{\star}$ & -.120 \\
\hline Exec Func & 234 & .047 & $3.762^{\star}$ & & $.175^{\star}$ & $-.247^{\star}$ & -.063 \\
\hline Epi Mem & 234 & .061 & $4.998 * \star$ & & .221 *夫 & .070 & -.072 \\
\hline Glob Cog & 234 & .130 & 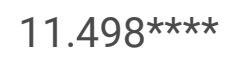 & & 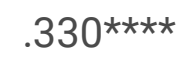 & -.148 & $-.117^{\star}$ \\
\hline Verb Flu & 234 & .043 & $3.449 *$ & \multirow[t]{5}{*}{ Hippocampal Volume } & .078 & $<-.001$ & $-.111 *$ \\
\hline $\begin{array}{l}\text { Proc } \\
\text { Speed }\end{array}$ & 234 & .061 & $5.014^{\star *}$ & & .034 & -.225 & $-.173^{\star \star}$ \\
\hline Exec Func & 234 & .030 & 2.339 & & .026 & -.190 & -.107 \\
\hline Epi Mem & 234 & .033 & 2.608 & & .032 & .142 & $-.127 \star$ \\
\hline Glob Cog & 234 & .069 & $5.671 * \star \star$ & & .061 & -.044 & $-.195^{\star \star}$ \\
\hline Verb Flu & 234 & .065 & $5.303^{\star \star}$ & \multirow{5}{*}{$\begin{array}{l}\text { Mean Cortical } \\
\text { Thickness }\end{array}$} & $.166^{\star \star}$ & -.024 & -.098 \\
\hline $\begin{array}{l}\text { Proc } \\
\text { Speed }\end{array}$ & 234 & .073 & $6.063^{\star \star \star}$ & & .129 & $-.252^{\star}$ & $-.152^{\star}$ \\
\hline Exec Func & 234 & .048 & $3.834^{\star}$ & & $.153^{*}$ & -.226 & -.077 \\
\hline Epi Mem & 234 & .053 & $4.281^{\star *}$ & & $.159 *$ & .106 & -.098 \\
\hline Glob Cog & 234 & .109 & $9.401^{\star \star \star \star}$ & & $.231^{\star \star \star}$ & -.092 & $-.158^{\star \star}$ \\
\hline
\end{tabular}

\section{Step 2a: Independent Effects}

Significant positive independent effects were observed for 18 proxies, including 2 individual proxies and 16 composites, across the 15 models in both datasets (see Additional file 1 for significant independent effects across both datasets; see Additional file 2 for all significant independent effects in TILDA; see Additional file 3 for all significant independent effects in CR/RANN). The proxy with the largest average independent effect was verbal intelligence (mean $R^{2}$ change $=0.10$; see Fig. 3 ). Verbal intelligence was the most robust proxy: independent effects were replicated across both datasets in $100 \%$ of models. The largest average independent effects were observed for verbal intelligence on global cognition where it explained a mean additional 16.80\% (hippocampal volume), 15.87\% (grey matter volume), and 14.66\% 
(mean cortical thickness) of the variance after accounting for age, sex, and brain structure (for scatter plots of proxies with 10 largest average independent effects, see Additional file 3, Fig. S1). Education was the only other individual proxy with reproducible independent effects (mean $R^{2}$ change $=0.05$ ), which were observed in $20 \%$ of models, all of which contained executive function.

The most robust composite proxy was comprised of occupational complexity and verbal intelligence (mean $\mathrm{R}^{2}$ change $=0.07$ ) which was replicated in $86.67 \%$ of models. The composite proxy with the largest average effect was educational attainment and verbal intelligence (mean $R^{2}$ change $=0.09$ ) which was replicated in $80 \%$ of models. Only one composite with reproducible independent effects - occupational complexity and physical activity - did not include verbal intelligence. This was the least robust composite as it was replicated in a single model and had the smallest average effect $\left(\right.$ mean $\mathrm{R}^{2}$ change $=$ 0.02).

[insert Fig. 3 here]

\section{Figure 3}

Mean $\mathrm{R}^{2}$ change across datasets in all models for proxies with significant effects.

+ indicate composite proxies (e.g. Education + Verbal IQ = composite of educational attainment and verbal intelligence). Black vertical bars represent the mean of significant $R^{2}$ change values across all models for that proxy. All models were adjusted for brain structure, age, and sex.

\section{[insert Fig. 4 here]}

\section{Figure 4}

Mean $\mathrm{R}^{2}$ change in all TILDA models for individual proxies with significant effects. Black vertical bars represent the mean of significant $R^{2}$ change values across all models for that proxy. All models were adjusted for brain structure, age, and sex.

[insert Fig. 5 here]

\section{Figure 5}

Mean $\mathrm{R}^{2}$ change in all TILDA models for composites proxies with significant effects. Each row refers to all composites including that proxy (e.g. Verbal IQ + refers to all composites including verbal intelligence). Black vertical bars represent the mean of significant $R^{2}$ change values across all models for all composites containing that proxy. All models were adjusted for brain structure, age, and sex.

\section{Step 2b: Additional Independent Effects}


Data was only available for cognitively stimulating activities and social engagement in TILDA.

Consequently, these effects could not be assessed in terms of their reproducibility. However, within TILDA, positive independent effects of cognitively stimulating activities on cognition were observed in $100 \%$ of models and this proxy had the second largest average independent effect of all individual proxies (mean $R^{2}$ change $=0.065$, see Fig. 4 ). In contrast, positive independent effects of social activities on cognition were observed in only $40 \%$ of models and this proxy had the second smallest average independent effect of all individual proxies (mean $\mathrm{R}^{2}$ change $=0.013$ ). The only individual proxy with smaller effects than social engagement was physical activity which did not have significant effects in any model.

Composite proxies including verbal intelligence had the largest average effects, followed by cognitively stimulating activities, and then education (see Fig. 5). Composites including verbal intelligence had significant effects in all models in TILDA. The composite with the largest effect in TILDA was verbal intelligence and cognitively stimulating activities (mean $R^{2}$ change $=0.13$ ). The only composite proxy which was not significant in any model was social engagement and physical activity.

\section{Step 3: Moderation Effects}

There were no significant moderation effects, in either dataset for any proxy, on the association between brain structure - as measured by GM volume, hippocampal volume, or mean cortical thickness - and cognition. Negative moderation effects are consistent with the $\mathrm{CR}$ hypothesis because they reflect weaker associations between brain structure and cognition in individuals with higher $\mathrm{CR}$, suggesting that individuals with higher $\mathrm{CR}$ are less reliant on brain structure to sustain cognitive function. 31 nonreplicated negative moderation effects (i.e., consistent with the $\mathrm{CR}$ hypothesis) were observed in TILDA (see Additional file 4, Table S1), but none survived correction for multiple comparisons (Bonferroniadjusted alpha $=0.0004$ : alpha [0.05] / comparisons per model [127]). $61.29 \%$ of these effects were observed for composite proxies including cognitively stimulating activities, which was not available in CR/RANN. No negative moderation effects were observed in CR/RANN.

Positive moderation effects contradict the CR hypothesis as they reflect stronger associations between brain structure and cognition in individuals with higher $\mathrm{CR}$, suggesting that individuals with higher $\mathrm{CR}$ are more reliant on brain structure to sustain cognitive function. Non-replicated positive moderation effects (i.e. contradicting the $\mathrm{CR}$ hypothesis) were observed in both datasets (see Additional file 4, Table S2) but none survived correction for multiple comparisons. Eight effects were observed in TILDA (Bonferroniadjusted alpha $=0.0004$ ) and seven effects were observed in CR/RANN (Bonferroni-adjusted alpha $=$ 0.0016: alpha [0.05] / comparisons per model [31]). The Bonferroni corrections for multiple comparisons applied here are liberal as they correct for number of proxies compared per brain-cognition model (TILDA: 127, CR/RANN: 31 ) rather than number of total comparisons across all proxies and all brain-cognition models (TILDA: 1905; CR/RANN: 465).

\section{Discussion}


The reproducibility and magnitude of moderation and independent effects of $33 \mathrm{CR}$ proxies, comprised of 5 standard individual proxies and all their unique combinations, were assessed across 2 datasets to investigate their validity as measures of $\mathrm{CR}$. No moderation effects of $\mathrm{CR}$ proxies on the association between brain structure - as measured by GM volume, hippocampal volume, or mean cortical thickness - and cognition were observed across both datasets. Replicated independent effects - positive associations with cognitive function, independent of brain structure - were observed for 2 individual proxies (verbal intelligence and educational attainment) and 16 composites. The most robust and largest effects on cognition were found for verbal intelligence, which satisfied the independent effect criterion in all 15 brain-cognition models across both datasets. Educational attainment satisfied the independent effect criterion in 3 brain-cognition models. No composite proxy had larger or more robust independent effects on cognition than verbal intelligence alone. Our results support the use of verbal intelligence as a proxy measure of CR in cross-sectional studies of cognitively healthy older adults.

\section{Verbal intelligence had larger and more robust effects on cognition than Educational attainment}

We found that verbal intelligence had the largest and most robust independent effects on cognition. Unlike previous studies, due to the availability of two large neuroimaging datasets, we could demonstrate that independent effects of verbal intelligence on cognition were present in several brain-cognition models and were replicable. This validation of verbal intelligence as a CR proxy supports previous, narrower, associations between verbal intelligence and cognitive function in the presence of hippocampal atrophy (56), a neuropathological 'residual' measure of CR (55), a functional connectivity measure of CR based on task potency (9), and a possible neuromarker of CR, locus coeruleus signal intensity (107).

Aside from verbal intelligence, the only other individual proxy with replicable independent effects on cognition was educational attainment. These replicable effects were only observed in brain-cognition models where executive function was the cognitive outcome variable. While education has been previously positively associated with executive function, without accounting for brain structure, in cognitively healthy older adults (108) and in a systematic review (50), our results show that this association is independent of GM volume, hippocampal volume, or mean cortical thickness. Notably, the effects of education were less robust than verbal intelligence, as positive associations were not seen across both datasets for verbal fluency, processing speed, episodic memory and global cognition. As such, these results suggest that educational attainment is not a reliable individual proxy of CR in cognitively healthy older adults. This conclusion is supported by previous findings including a systematic review which found positive evidence for education in only $38 \%$ of complete models with cognitively healthy samples (53) and a non-significant association between education (when considered separately from other possible CR proxies) and a neuropathological residual measure of CR (54). Based on their findings using ex-vivo neuropathological measures, Reed et al. (54) concluded that the observed effects of education on cognition should not be simply considered as reserve effects. Our results further show 
that this conclusion is valid when using in-vivo neuroimaging measures of GM volume, hippocampal volume, or mean cortical thickness.

The general finding that verbal intelligence had larger and more robust CR effects than educational attainment convincingly supports an argument favoring the use of verbal intelligence over education (80). This argument was previously broadly supported by evidence that, compared to educational attainment, verbal intelligence was a stronger predictor of cognitive function/decline $(109,110)$ and had greater protective effects on the onset of clinical symptoms of MCI/AD (43,111). More specifically, MalekAhmadi et al. (31) directly compared educational attainment and verbal intelligence in a mixed autopsy sample, consisting of adults with diagnoses of no cognitive impairment, $\mathrm{MCl}$ and $\mathrm{AD}$. In complete $\mathrm{CR}$ models, including neuropathological indices and measures of episodic memory and executive function, positive evidence was found for verbal intelligence, but not education, as a CR proxy, leading to the conclusion that verbal intelligence measures are superior to educational attainment as CR proxies. Here, we have shown that verbal intelligence is also a superior CR proxy when using in-vivo measures of GM volume, hippocampal volume, or mean cortical thickness and when assessed in respect to additional cognitive outcome measures, including verbal fluency, processing speed, and global cognition. Importantly, our results show that this conclusion holds when tested across two separate samples of cognitively healthy older adults.

The larger and more robust effects of verbal intelligence on cognition reported here and elsewhere could be explained by 2 key factors. Firstly, verbal intelligence may be a closer reflection of the quality, benefit, or outcomes of educational attainment (112) than years of education, which simply reflects the quantity of educational attainment. Quality of education can differ greatly among individuals with the same quantity of education due to various socioeconomic and systemic factors (113), such as class size (114), and also due to individual level factors such as intrinsic learning motivation and academic self-efficacy (115). Secondly, measures of verbal intelligence may reflect wider lifetime educational and cognitive experiences as compared to years of education which is generally restricted to early-life formal education (80-83) and typically neglects to consider later-life education which has been positively associated with cognitive function $(116,117)$. In this sense, verbal intelligence could be considered a dynamic CR proxy which can change over time $(118,119)$, as it may increase from young to mid-adulthood before decreasing in older adulthood (120). In contrast, years of education may be considered a static CR proxy (31). Despite the widespread use of educational attainment as an individual CR proxy, our results suggest that it should only be used as an individual proxy where verbal intelligence is not available.

\section{Composite proxies are had smaller and less robust effects on cognition than Verbal intelligence}

We found significant positive independent effects of 16 different composite proxies on cognition across both datasets. 3 of these composites had significant effects on cognition in at least two thirds of the brain-cognition models assessed: occupational complexity and verbal intelligence ( $86.67 \%$ of models); education and verbal intelligence ( $80 \%$ of models); and education, occupational complexity, and verbal 
intelligence ( $66.67 \%$ of models). This is a novel finding as the most robust composite - occupational complexity and verbal intelligence - has never (to the best of our knowledge) been used previously as a CR proxy, likely due to the predominant use of education both as an individual proxy and in composites. The next most robust composite of education and verbal intelligence has been widely used $(42,43,45,46,59,78,111)$ and our results support a previous positive association between this composite and episodic memory, controlling for GM volume (59). A speculative explanation for the greater robustness of occupational complexity and verbal intelligence as a composite may be that occupational complexity and verbal intelligence are less strongly correlated with each other than educational attainment and verbal intelligence (see Fig. 2).

While composite proxies purportedly provide advantages over individual proxies, our results show that their independent effects on cognition are less robust (i.e. less frequently observed across brain-cognition models) and smaller in magnitude than those found for verbal intelligence alone. This may be explained by the large individual effects of verbal intelligence on cognition and its strong correlation with other proxies (see Fig. 2) considering that all composite proxies with replicated effects contained verbal intelligence, except for the composite with the least robust effects, occupational complexity and physical activity. While adding another proxy to verbal intelligence to form a composite should have an additive effect, this could also add noise to an already strong proxy measure as well as shared variance in situations where the proxies are correlated. Consequently, the overall effect of the composite may then be smaller than verbal intelligence alone. Alternative methods to creating composites, such as principal components analysis, could potentially mitigate this issue but may not be theoretically appropriate (35) and incorporating this method within the analysis framework used here would have significantly increased the complexity of the analysis. Of all composites considered here, our results especially support the use of education and verbal intelligence as well as occupational complexity and verbal intelligence as composite proxies where multiple proxies are available. However, using composites may lead to more Type II errors than using verbal intelligence alone, given the more robust and larger effects of verbal intelligence. As such, our results suggest that researchers should use, or at least repeat analyses using, verbal intelligence alone, in cross-sectional studies of cognitively healthy older adults.

\section{Occupational complexity, leisure activities, and physical activity did not show robust effects on cognition}

We did not find any evidence for robust independent effects of 3 individual proxies on cognition across both datasets. Occupational complexity was not positively associated with any domain of cognitive function, adjusting for GM volume, hippocampal volume, or mean cortical thickness. This suggests that the small positive associations between this proxy and cognition, as reported in a meta-analysis (50), may not be independent of these measures of brain structure. Unlike the detailed nature of the occupational complexity measure used here, occupational complexity has been typically measured using government classification codes that are effectively a socioeconomic classification of occupations (e.g., the UK's Office Of Population Statistic classification as in Staff et al., 2004). As such, previously reported effects for occupational complexity may have in fact reflected the effect of socioeconomic status, which

Page $17 / 35$ 
can support cognitive health via greater access to resources and healthcare, among many other mechanisms (35). While Chapko et al. (53) concluded that the evidence for this proxy in complete CR models using cognitively healthy samples was inconclusive, our results, do not support the use of occupational complexity as a proxy measure of CR in cross-sectional studies of cognitively healthy older adults.

As with occupational complexity, we did not find robust evidence to support the use of leisure activities as an individual CR proxy. Although it has been associated with a reduced risk of dementia and $A D(122$, but cf. 123), few studies have rigorously tested this proxy in a complete CR model. One study found a moderation effect for midlife leisure activities but in line with our findings, they did not find evidence of either a moderation or independent effect for later life leisure activities (124). Future research is warranted to clarify which specific leisure activities should be included in measures for this proxy given that only a few activities have been associated with cognition in mid-/old-age samples, albeit without adjusting for brain structure $(116,125)$. However, our results do not support the use of later life leisure activities as a proxy measure of CR in cross-sectional studies of cognitively healthy older adults.

Finally, our results do not support the use of physical activity as an individual CR proxy. While this proxy has been previously associated with cognitive function in older adults without controlling for brain structure $(126,127)$, our results show that these associations are not independent of GM volume, hippocampal volume, or mean cortical thickness. This supports previous findings of non-significant associations from the few complete CR models assessing this proxy adjusting for brain structure using GM volume and hippocampal atrophy $(56,101)$. The disparity in the observed associations when brain structure is accounted for could be because the protective effects of exercise may be exerted via improved brain maintenance, i.e. the relative preservation of brain structural health $(8,128)$, rather than improved CR (129). This is supported by the finding that the protective effects of exercise on cognition were mediated by increases in prefrontal cortex volume (130) and also by associations of greater physical activity with lower brain-predicted age difference scores (131), which reflects better brain maintenance (132), and greater cortical thickness (133) and regional GM volumes (134,135). Setting aside a possible contribution of physical activity to brain maintenance, our results suggests that it does not contribute to greater $\mathrm{CR}$ and therefore do not support the use of physical activity as a proxy measure of $\mathrm{CR}$ in cross-sectional studies of cognitively healthy older adults.

\section{Lack of evidence for moderation effects of CR proxies}

Robust moderation effects of CR proxies on the association between brain structure - as measured by GM volume, hippocampal volume, or mean cortical thickness - and cognition were not identified here. This lack of evidence is in line with previously reported non-significant moderation effects on the relationship between episodic memory and GM volume (59) and right hippocampal volume (103) but conflicts with previous evidence of significant moderation effects reported for CR proxies in similar braincognition models $(46,124,136)$. However, the evidence for moderation is largely inconsistent as highlighted by the finding of moderation effects reported on 1 measure, but not on 2 other measures, of episodic memory within the same study (136) and even findings of a positive moderation effect, which 
contradicts the $\mathrm{CR}$ hypothesis, on the relationship between left hippocampal volume and episodic memory (103). It is likely that our non-significant effects highlights the general difficulties in detecting CR moderation effects.

The ability to detect a moderation effect here may have been impaired because the participants were cognitively and neurologically healthy and therefore had a relatively restricted range of cognitive function and brain atrophy in comparison to cognitively and/or neurologically impaired individuals. The relatively restricted range of the predictor variable of brain structure restricts the range of the interaction term (137) which can substantially reduce statistical power to detect a moderation effect (138). This is exacerbated by the fact that neuroimaging variables explain a relatively small amount $(20 \%)$ of variance in healthy older adults cognition (2), which effectively constrains the size of the moderation effect (62). While the present study was designed using pre-existing data from two cognitively and neurologically healthy cohorts, an experimental approach where individuals with extremely low or high scores on measures of cognitive reserve and brain structure are oversampled may be better able to detect the existence of a moderation effect for these proxies (137).

\section{Promising evidence for Cognitively stimulating activities but not Social engagement as proxies but replication required}

We were unable to assess the reproducibility of the effects of cognitively stimulating activities and social engagement on cognition across datasets as we only had sufficient data in TILDA for these proxies. Within TILDA, cognitively stimulating activities was highly robust as it had positive independent effects on cognition in all brain-cognition models, and had the largest average independent effect on cognition after verbal intelligence. This finding supports associations between this proxy and neuropathological 'residual' measures of CR $(54,55)$ and suggests that previously reported consistent positive associations $(49,50)$ can be observed with several cognition domains when controlling for brain structure, as measured by GM volume, hippocampal volume, and mean cortical thickness. Social engagement was less robust as it had positive independent effects on cognition in only $40 \%$ of brain-cognition models and had the second smallest average independent effect on cognition of all individual proxies. This inconsistent evidence emphasises a need for further study of social engagement in complete CR models. While mixed evidence of moderation effects have been reported to-date for this proxy controlling for neuropathology $(58,139)$, this is the first attempt to assess it in a complete CR model including neuroimaging variables. As our focus was on replication across datasets rather than single dataset findings requiring correction for multiple comparisons and because this proxy was only available in a single dataset, these findings remain speculative until they can be replicated. With this in mind, while we cannot make definitive conclusions, we can tentatively suggest that cognitively stimulating activities may be a reasonable choice of CR proxy where verbal intelligence is not available and that social engagement should not be used as an individual proxy.

\section{Limitations}


The present study provides data-driven evidence supporting the use of specific proxies to measure CR in cross-sectional studies of cognitively healthy older adults. Nonetheless, there are some limitations which, if addressed in future research, could further strengthen these recommendations and provide additional insights. The main limitation of the present results are that they are cross-sectional. As such, we cannot make solid inferences about the casual direction of the relationships between the robust proxies and cognitive function. Similarly, while CR is supposed to protect against cognitive decline, our analysis only provides information about its association with individual differences in cognitive function, not decline. Future analyses after further waves of data collection will be necessary to assess whether the effects of these proxies are consistent when assessed in the context of cognitive decline.

Another limitation is that the $\mathrm{CR}$ models used here were limited to three brain structure variables: GM volume, hippocampal volume, and mean cortical thickness. Aside from hippocampal volume, the CR models did not contain regional measures such as parietotemporal cortical thickness or measures of WM microstructural integrity, WM hyperintensity volume, or AD-related neuropathology. As CR proxies have been previously reported to moderate the relationship between these measures and cognition $(43,83,140-$ 143), future studies could assess proxies in complete CR models containing these brain structure variables to extend the conclusions made here to a wider spectrum of brain-cognition relationships. Furthermore, there were differences in the relationship between age and cognition across both datasets. Age was negatively associated with cognition in $100 \%$ of brain-cognition models in TILDA, but only in $40 \%$ of models in CR/RANN. Tentative explanations for these differences may have been the larger sample size and older age of the TILDA brain-cognition models. Finally, some CR proxies, namely leisure activities and physical activity were measured differently in both datasets. Differences in these measures or in the specific activities included in each measure may have contributed to differing effects across both datasets. This may be particularly pertinent for leisure activities as its relationship with cognitive function can vary based on the specific leisure activities assessed (116). However, this variability across the two datasets reflects the typical variability in the measurement of $\mathrm{CR}$ with proxies.

\section{Conclusions}

Despite the discussed limitations, the present findings are informative for researchers using proxies as measures of CR. We built on previous meta-analyses and systematic reviews of CR proxies by assessing a wider set of standard proxies, including their composites, and evaluating their effects across complete and theoretically consistent models of CR and in multiple brain-cognition relationships. Our analysis framework enabled the comparison of the robustness and magnitude of effects. Furthermore, the reported findings are stringent, robust and replicable, as they were only considered statistically significant if they were replicated in a robust regression and across two datasets.

The present study is the first systematic investigation of the validity of different proxies, and their composites, in complete CR models. Verbal intelligence was associated with better cognitive function in all variables assessed, controlling for mean cortical thickness, GM volume, and hippocampal volume. The independent effects on cognition of education and composite proxies, including verbal intelligence and 
occupational complexity as well as verbal intelligence and education, were smaller and less robust. Our results suggest that, in cross-sectional studies of cognitively healthy older adults, verbal intelligence should be used as a CR proxy, over other proxies including education, occupational complexity, leisure activities, exercise, and composites including all possible combinations of these proxies. While no robust moderation effects of CR proxies on the association between brain structure - as measured by GM volume, hippocampal volume, or mean cortical thickness - and cognition were found here, this may be due to the considerable statistical difficulties in detecting such effects in normal healthy ageing samples. In sum, the finding of robust independent effects across all brain-cognitive domains assessed provides strong evidence for the use of verbal intelligence as a CR proxy.

\section{Declarations}

\section{Ethics approval and consent to participate}

All procedures performed in studies involving human participants were in accordance with the ethical standards of the institutional research committees and with the 1964 Helsinki declaration and its later amendments or comparable ethical standards. Informed consent was obtained from all individual participants included in the study.

\section{Consent for publication}

Not applicable

\section{Competing interests}

The authors declare that they have no competing interests.

\section{Funding}

RB is supported by the Irish Research Council under grant number EPSPG/2017/277. YS is supported by NIA RF1 AG038465 and R01 AG026158. SPK is supported by Science Foundation Ireland grant number 18/FRL/6188. The TILDA MRI study was funded by the Health Research Board grant number HRA-PHR2014-667. TILDA is funded by core grants from the Health Research Board, Atlantic Philanthropies and Irish Life. The National Centre for Advanced Medical Imaging (CAMI) is grant-funded by the Health Research Board. The funding agencies had no involvement in the conduct of the research or preparation of the article.

\section{Acknowledgements}


The authors would like to thank all participants for the time and effort they generously gave to participate in the TILDA and CR/RANN studies. IHR thanks The Atlantic Philanthropies for their grant to the Global Brain Health Institute. MRI data collection in TILDA was supported by Prof. James Meaney and Dr. Jason McMorrow in the National Centre for Advanced Medical Imaging (CAMI) at St. James' Hospital, Dublin.

\section{Authors' contributions}

Study conception and design (RB and RW, in consultation with IHR and YS); TILDA data collection, preparation, and co-ordination (CDL, SPK, SS, RAK); CR/RANN data collection and co-ordination (YS); statistical analysis, data interpretation, and drafting the manuscript (RB and RW). All authors provided feedback and revisions on the manuscript and approved the final version for submission.

\section{References}

1. Boyle PA, Wilson RS, Yu L, Barr AM, Honer WG, Schneider JA, et al. Much of late life cognitive decline is not due to common neurodegenerative pathologies. Ann Neurol. 2013 Sep;74(3):478-89.

2. Hedden T, Schultz AP, Rieckmann A, Mormino EC, Johnson KA, Sperling RA, et al. Multiple Brain Markers are Linked to Age-Related Variation in Cognition. Cereb Cortex. 2014 Oct;14(4):1388-400. 26(.

3. Katzman R, Terry R, DeTeresa R, Brown T, Davies P, Fuld P, et al. Clinical, pathological, and neurochemical changes in dementia: A subgroup with preserved mental status and numerous neocortical plaques. Ann Neurol. 1988 Feb;23(2):138-44.

4. Bennett DA, Schneider JA, Arvanitakis Z, Kelly JF, Aggarwal NT, Shah RC, et al. Neuropathology of older persons without cognitive impairment from two community-based studies. Neurology. 2006 Jun;66(12):1837-44.

5. Stern Y. What is cognitive reserve? Theory and research application of the reserve concept. J Int Neuropsychol Soc. 2002 Mar;8(3):448-60.

6. Tucker AM, Stern Y. Cognitive reserve in aging. Curr Alzheimer Res. 2011 Jun;8(4):354-60.

7. Mondini S, Madella I, Zangrossi A, Bigolin A, Tomasi C, Michieletto M, et al. Cognitive Reserve in Dementia: Implications for Cognitive Training. Vol. 8, Frontiers in Aging Neuroscience. 2016. p. 84.

8. Stern Y, Arenaza-Urquijo EM, Bartrés-Faz D, Belleville S, Cantilon M, Chetelat G, et al. Whitepaper: Defining and investigating cognitive reserve, brain reserve, and brain maintenance. Alzheimer's Dement. 2020 Sep 14;16(9):1305-11.

9. van Loenhoud AC, Habeck C, van der Flier WM, Ossenkoppele R, Stern Y. Identifying a task-invariant cognitive reserve network using task potency. Neuroimage. 2020 Apr 15;210:116593.

10. Sarracanie M, Lapierre CD, Salameh N, Waddington DEJ, Witzel T, Rosen MS. Low-Cost HighPerformance MRI. Sci Rep. 2015 Oct;15(1):1-9. 5(. 
11. Ogbole GI, Adeyomoye AO, Badu-Peprah A, Mensah Y, Nzeh DA. Survey of magnetic resonance imaging availability in West Africa. Pan Afr Med J. 2018;30:240.

12. Wang HX, Gustafson DR, Kivipelto M, Pedersen NL, Skoog I, Windblad B, et al. Education halves the risk of dementia due to apolipoprotein $\varepsilon 4$ allele: A collaborative study from the Swedish Brain Power initiative. Neurobiol Aging. 2012 May 1;33(5):1007.e1-1007.e7.

13. Xu W, Tan L, Wang HF, Tan MS, Tan L, Li JQ, et al. Education and Risk of Dementia: Dose-Response Meta-Analysis of Prospective Cohort Studies. Vol. 53: Molecular Neurobiology. Humana Press Inc.; 2016. pp. 3113-23.

14. Dekhtyar S, Wang H-X, Fratiglioni L, Herlitz A. Childhood school performance, education and occupational complexity: a life-course study of dementia in the Kungsholmen Project. Int $\mathrm{J}$ Epidemiol. 2016 Mar 10;45(4):1207-15.

15. Kröger E, Andel R, Lindsay J, Benounissa Z, Verreault R, Laurin D. Is Complexity of Work Associated with Risk of Dementia?: The Canadian Study of Health and Aging. Am J Epidemiol. 2008 Feb 7;167(7):820-30.

16. Andel R, Crowe M, Pedersen NL, Mortimer J, Crimmins E, Johansson B, et al. Complexity of Work and Risk of Alzheimer's Disease: A Population-Based Study of Swedish Twins. Journals Gerontol Ser B. 2005 Sep 1;60(5):P251-8.

17. Potter GG, Helms MJ, Burke JR, Steffens DC, Plassman BL. Job demands and dementia risk among male twin pairs. Alzheimer's Dement. 2007 Jul 1;3(3):192-9.

18. Kaup AR, Simonsick EM, Harris TB, Satterfield S, Metti AL, Ayonayon HN, et al. Older Adults With Limited Literacy Are at Increased Risk for Likely Dementia. Journals Gerontol Ser A. 2013 Oct;24(7):900-6. 69(.

19. Cervilla JA, Prince M, Joels S, Lovestone S, Mann A. Long-term predictors of cognitive outcome in a cohort of older people with hypertension. Br J Psychiatry. 2000;177(JUL.):66-71.

20. Pavlik VN, Doody RS, Massman PJ, Chan W. Influence of Premorbid IQ and Education on Progression of Alzheimer's Disease. Dement Geriatr Cogn Disord. 2006 Oct;22(4):367-77.

21. Manly JJ, Touradji P, Tang MX, Stern Y. Literacy and memory decline among ethnically diverse elders. J Clin Exp Neuropsychol. 2003 Aug;25(5):680-90.

22. Marioni RE, Proust-Lima C, Amieva H, Brayne C, Matthews FE, Dartigues JF, et al. Social activity, cognitive decline and dementia risk: A 20-year prospective cohort study Chronic Disease epidemiology. BMC Public Health. 2015 Oct;24(1):1089. 15(.

23. Wang HX, Karp A, Winblad B, Fratiglioni L. Late-Life Engagement in Social and Leisure Activities Is Associated with a Decreased Risk of Dementia: A Longitudinal Study from the Kungsholmen Project. Am J Epidemiol. 2002 Jun;15(12):1081-7. 155.

24. Akbaraly TN, Portet F, Fustinoni S, Dartigues J-F, Artero S, Rouaud O, et al. Leisure activities and the risk of dementia in the elderly: results from the Three-City Study. Neurology. 2009 Sep;15(11):85461. 73(. 
25. Paillard-Borg S, Fratiglioni L, Winblad B, Wang HX. Leisure activities in late life in relation to dementia risk: Principal component analysis. Dement Geriatr Cogn Disord. 2009 Sep;28(2):136-44.

26. Bowen ME. A Prospective Examination of the Relationship between Physical Activity and Dementia Risk in Later Life. Am J Heal Promot. 2012 Jul 1;26(6):333-40.

27. Rovio S, Kåreholt I, Helkala EL, Viitanen M, Winblad B, Tuomilehto J, et al. Leisure-time physical activity at midlife and the risk of dementia and Alzheimer's disease. Lancet Neurol. 2005 Nov;4(11) (1):705-11.

28. Ogino E, Manly JJ, Schupf N, Mayeux R, Gu Y. Current and past leisure time physical activity in relation to risk of Alzheimer's disease in older adults. Alzheimer's Dement. 2019 Dec 1;15(12):160311.

29. Zhou Z, Wang P, Fang Y. Social Engagement and Its Change are Associated with Dementia Risk among Chinese Older Adults: A Longitudinal Study. Sci Rep. 2018 Dec;8(1)(1):1-7.

30. Stern Y, Barulli D. Chapter 11 - Cognitive reserve. In: Dekosky ST, Asthana SBT-H of CN, editors. Geriatric Neurology. Elsevier; 2019. p. 181-90.

31. Malek-Ahmadi M, Lu S, Chan Y, Perez SE, Chen K, Mufson EJ. Static and Dynamic Cognitive Reserve Proxy Measures: Interactions with Alzheimer's Disease Neuropathology and Cognition. J Alzheimer's Dis Park. 2017;07(06).

32. Bettcher BM, Gross AL, Gavett BE, Widaman KF, Fletcher E, Dowling NM, et al. Dynamic change of cognitive reserve: associations with changes in brain, cognition, and diagnosis. Neurobiol Aging. 2019 Nov 1;83:95-104.

33. Zahodne LB, Manly JJ, Brickman AM, Siedlecki KL, Decarli C, Stern Y. Quantifying Cognitive Reserve in Older Adults by Decomposing Episodic Memory Variance: Replication and Extension. J Int Neuropsychol Soc. 2013;19:1-9.

34. Kartschmit N, Mikolajczyk R, Schubert T, Lacruz ME. Measuring Cognitive Reserve (CR) - A systematic review of measurement properties of $C R$ questionnaires for the adult population. PLoS One. 2019 Aug 7;14(8):e0219851-e0219851.

35. Jones RN, Manly J, Glymour MM, Rentz DM, Jefferson AL, Stern Y. Conceptual and Measurement Challenges in Research on Cognitive Reserve. J Int Neuropsychol Soc. 2011 Jun 17;17(04):593-601.

36. Sirin SR. Socioeconomic Status and Academic Achievement: A Meta-Analytic Review of Research. Rev Educ Res. 2005 Sep 1;75(3):417-53.

37. Marden JR, Tchetgen Tchetgen EJ, Kawachi I, Glymour MM. Contribution of Socioeconomic Status at 3 Life-Course Periods to Late-Life Memory Function and Decline: Early and Late Predictors of Dementia Risk. Am J Epidemiol. 2017 May;24(7):805-14. 186(.

38. Yaffe K, Falvey C, Harris TB, Newman A, Satterfield S, Koster A, et al. Effect of socioeconomic disparities on incidence of dementia among biracial older adults: Prospective study. BMJ. 2013 Dec $19 ; 347$.

39. Fischer C, Yeung E, Hansen T, Gibbons S, Fornazzari L, Ringer L, et al. Impact of socioeconomic status on the prevalence of dementia in an inner city memory disorders clinic. Int Psychogeriatrics. 
2009 Dec 28;21(6):1096-104.

40. Lövdén M, Fratiglioni L, Glymour MM, Lindenberger U, Tucker-Drob EM. Education and Cognitive Functioning Across the Life Span. Psychol Sci Public Interes. 2020 Aug 1;21(1):6-41.

41. Zahodne LB, Stern Y, Manly JJ. Differing effects of education on cognitive decline in diverse elders with low versus high educational attainment. Neuropsychology. 2015 Jul 1;29(4):649-57.

42. Fleck JI, Kuti J, Mercurio J, Mullen S, Austin K, Pereira O. The impact of age and cognitive reserve on resting-state brain connectivity. Front Aging Neurosci. 2017 Dec 1;9(DEC).

43. Pettigrew C, Soldan A, Zhu Y, Wang MC, Brown T, Miller M, et al. Cognitive reserve and cortical thickness in preclinical Alzheimer's disease. Brain Imaging Behav. 2017 Apr 1;11(2):357-67.

44. Pettigrew C, Soldan A, Zhu Y, Cai Q, Wang MC, Moghekar A, et al. Cognitive reserve and rate of change in Alzheimer's and cerebrovascular disease biomarkers among cognitively normal individuals. Neurobiol Aging. 2020 Apr 1;88:33-41.

45. Soldan A, Pettigrew C, Cai Q, Wang J, Wang MC, Moghekar A, et al. Cognitive reserve and long-term change in cognition in aging and preclinical Alzheimer's disease. Neurobiol Aging. 2017 Dec 1;60:164-72.

46. Steffener J, Barulli D, Habeck C, O'Shea D, Razlighi Q, Stern Y. The Role of Education and Verbal Abilities in Altering the Effect of Age-Related Gray Matter Differences on Cognition. Chao L, editor. PLoS One. 2014 Mar 13;9(3):e91196.

47. Stern $Y$, Habeck C. Deriving and testing the validity of cognitive reserve candidates. In: Perneczky, Robert G, editor. Neuromethods. New York: Humana Press; 2018. pp. 63-70.

48. Franzmeier N, Duering M, Weiner M, Dichgans M, Ewers M. Left frontal cortex connectivity underlies cognitive reserve in prodromal Alzheimer disease. Neurology. 2017 Mar;14(11):1054-61. 88(.

49. Harrison SL, Sajjad A, Bramer WM, Ikram MA, Tiemeier H, Stephan BCM. Exploring strategies to operationalize cognitive reserve: A systematic review of reviews. J Clin Exp Neuropsychol. 2015;37(3):253-64.

50. Opdebeeck C, Martyr A, Clare L. Cognitive reserve and cognitive function in healthy older people: a meta-analysis. Aging Neuropsychol Cogn. 2016 Jan;23(1)(2):40-60.

51. Wicherts JM, Veldkamp CLS, Augusteijn HEM, Bakker M, van Aert RCM, van Assen MALM. Degrees of Freedom in Planning, Running, Analyzing, and Reporting Psychological Studies: A Checklist to Avoid p-Hacking. Front Psychol. 2016 Nov 25;7(NOV):1832.

52. Christensen $\mathrm{H}$, Anstey KJ, Leach LS, Mackinnon AJ. Intelligence, education, and the brain reserve hypothesis. The handbook of aging and cognition, 3rd ed. New York: Psychology Press; 2008. pp. 133-88.

53. Chapko D, McCormack R, Black C, Staff R, Murray A. Life-course determinants of cognitive reserve (CR) in cognitive aging and dementia-a systematic literature review. Vol. 22: Aging and Mental Health. Routledge; 2018. pp. 915-26. 
54. Reed BR, Dowling M, Tomaszewski Farias S, Sonnen J, Strauss M, Schneider JA, et al. Cognitive activities during adulthood are more important than education in building reserve. $\mathrm{J}$ Int Neuropsychol Soc. 2011 Jul;17(4):615-24.

55. Negash S, Wilson R, Leurgans S, Wolk D, Schneider J, Buchman A, et al. Resilient Brain Aging: Characterization of Discordance between Alzheimer's Disease Pathology and Cognition. Curr Alzheimer Res. 2013 Oct 16;10(8):844-51.

56. Topiwala A, Suri S, Allan C, Valkanova V, Filippini N, Sexton CE, et al. Predicting cognitive resilience from midlife lifestyle and multi-modal MRI: A 30-year prospective cohort study. Ginsberg SD, editor. PLoS One. 2019 Feb 19;14(2):e0211273.

57. Buchman AS, Yu L, Wilson RS, Lim A, Dawe RJ, Gaiteri C, et al. Physical activity, common brain pathologies, and cognition in community-dwelling older adults. Neurology. 2019 Feb;19(8):E811-22. 92.

58. Biddle KD, d'Oleire Uquillas F, Jacobs HIL, Zide B, Kirn DR, Rentz DM, et al. Social Engagement and Amyloid- $\beta$-Related Cognitive Decline in Cognitively Normal Older Adults. Am J Geriatr Psychiatry. 2019 Nov;27(11)(1):1247-56.

59. Kwak S, Shin M, Kim H, Cho B, Ha J, Han G, et al. Moderating effect of cognitive reserve on the association between grey matter atrophy and memory varies with age in older adults.

Psychogeriatrics. 2020 Jan 8;20(1):87-95.

60. Morris JH, Sherman JD, Mansfield ER. Failures to Detect Moderating Effects With Ordinary Least Squares-Moderated Multiple Regression. Some Reasons and a Remedy. Psychol Bull. 1986 Mar;99(2):282-8.

61. Champoux JE, Peters WS. Form, effect size and power in moderated regression analysis. J Occup Psychol. 1987 Sep 1;60(3):243-55.

62. Whisman MA, McClelland GH. Designing, testing, and interpreting interactions and moderator effects in family research. J Fam Psychol. 2005 Mar;19(1):111-20.

63. Dunlap WP, Kemery ER. Effects of predictor intercorrelations and reliabilities on moderated multiple regression. Organ Behav Hum Decis Process. 1988 Apr 1;41(2):248-58.

64. Kearney PM, Cronin H, O'Regan C, Kamiya Y, Savva GM, Whelan B, et al. Cohort Profile: The Irish Longitudinal Study on Ageing. Int J Epidemiol. 2011 Aug 1;40(4):877-84.

65. Whelan BJ, Savva GM. Design and Methodology of The Irish Longitudinal Study on Ageing. J Am Geriatr Soc. 2013 May;61:265-8.

66. Donoghue OA, McGarrigle CA, Foley M, Fagan A, Meaney J, Kenny RA. Cohort Profile Update: The Irish Longitudinal Study on Ageing (TILDA). Int J Epidemiol. 2018 Oct 1;47(5):1398-1398I.

67. Stern Y, Gazes Y, Razlighi Q, Steffener J, Habeck C. A task-invariant cognitive reserve network. Neuroimage. 2018 Sep 1;178:36-45.

68. Habeck C, Gazes Y, Razlighi Q, Steffener J, Brickman A, Barulli D, et al. The Reference Ability Neural Network Study: Life-time stability of reference-ability neural networks derived from task maps of young adults. Neuroimage. 2016 Jan 15;125:693-704. 
69. Stern Y, Habeck C, Steffener J, Barulli D, Gazes Y, Razlighi Q, et al. The Reference Ability Neural Network Study: Motivation, design, and initial feasibility analyses. Neuroimage. 2014 Dec 1;103:139-51.

70. Henretta JC, McCrory C. Childhood Circumstances and Mid-Life Functional Mobility. J Aging Health. 2016 Apr 6;28(3):440-59.

71. Smart EL, Gow AJ, Deary IJ. Occupational complexity and lifetime cognitive abilities. Neurology. 2014 Dec 1;83(24):2285-91.

72. United States Employment Service. Dictionary of Occupational Titles. 4th ed. Washington, DC: Superintendent of Documents, US Government Printing Office.

73. Nelson HE, Willinson J. The National Adult Reading Test (NART): Test Manual. Windsor: Nelson; 1982.

74. Grober E, Sliwinski M. Development and validation of a model for estimating premorbid verbal intelligence in the elderly. J Clin Exp Neuropsychol. 1991.

75. Strauss EH, Sherman EMS, Spreen O. A Compendium of Neuropsychological Tests; Administration Norms And Commentary. 3rd ed. New York: Oxford University Press; 2006.

76. Beardsall L, Brayne C. Estimation of verbal intelligence in an elderly community: A prediction analysis using a shortened NART. Br J Clin Psychol. 1990.

77. Boyle R, Jollans L, Rueda-Delgado LM, Rizzo R, Yener GG, McMorrow JP, et al. Brain-predicted age difference score is related to specific cognitive functions: a multi-site replication analysis. Brain Imaging Behav. 2020.

78. Oosterman JM, Jansen MG, Scherder EJA, Kessels RPC. Cognitive reserve relates to executive functioning in the old-old. Aging Clin Exp Res. 2020 Dec 6;1-6.

79. Hatch SL, Feinstein L, Link BG, Wadsworth MEJ, Richards M. The Continuing Benefits of Education: Adult Education and Midlife Cognitive Ability in the British 1946 Birth Cohort. Journals Gerontol Ser B Psychol Sci Soc Sci. 2007 Nov;1(6):404-14. 62(.

80. Perneczky R, Kempermann G, Korczyn AD, Matthews FE, Ikram MA, Scarmeas N, et al. Translational research on reserve against neurodegenerative disease: Consensus report of the International Conference on Cognitive Reserve in the Dementias and the Alzheimer's Association Reserve, Resilience and Protective Factors Professional Interest Ar. BMC Medicine. 2019.

81. Schwartz CE, Rapkin BD, Healy BC. Reserve and Reserve-building activities research: Key challenges and future directions. BMC Neurosci. 2016 Sep 15;17(1):62.

82. Oh H, Razlighi QR, Stern Y. Multiple pathways of reserve simultaneously present in cognitively normal older adults. Neurology. 2018 Jan 16;90(3):E197-205.

83. Baker LM, Laidlaw DH, Cabeen R, Akbudak E, Conturo TE, Correia S, et al. Cognitive reserve moderates the relationship between neuropsychological performance and white matter fiber bundle length in healthy older adults. Brain Imaging Behav. 2017 Jun 1;11(3):632-9. 
84. Craig CL, Marshall AL, Sjöström M, Bauman AE, Booth ML, Ainsworth BE, et al. International Physical Activity Questionnaire: 12-Country Reliability and Validity. Med Sci Sport Exerc. 2003 Aug;35(8) (1):1381-95.

85. Lee PH, Macfarlane DJ, Lam TH, Stewart SM. Validity of the international physical activity questionnaire short form (IPAQ-SF): A systematic review. Vol. 8: International Journal of Behavioral Nutrition and Physical Activity. BioMed Central; 2011. pp. 1-11.

86. Godin G, Shephard RJ. A simple method to assess exercise behavior in the community. Can J Appl Sport Sci J Can des Sci Appl au Sport. 1985 Sep;10(3):141-6.

87. Scarmeas N, Luchsinger JA, Schupf N, Brickman AM, Cosentino S, Tang MX, et al. Physical activity, diet, and risk of Alzheimer disease. JAMA - J Am Med Assoc. 2009 Aug 12;302(6):627-37.

88. Berkman LF, Syme SL. Social networks, host resistance, and mortality: A nine-year follow-up study of alameda county residents. Am J Epidemiol. 1979;109(2):186-204.

89. McCrory C, Finucane C, O'Hare C, Frewen J, Nolan H, Layte R, et al. Social Disadvantage and Social Isolation Are Associated With a Higher Resting Heart Rate: Evidence From The Irish Longitudinal Study on Ageing. Journals Gerontol Ser B. 2016 Dec 6;71(3):463-73.

90. Leys C, Ley C, Klein O, Bernard P, Licata L. Detecting outliers: Do not use standard deviation around the mean, use absolute deviation around the median. J Exp Soc Psychol. 2013 Jul 1;49(4):764-6.

91. D’Elia LF, Satz P, Uchiyama CL, White T. Color Trials Test. Professional Manual. Odessa: Psychological Assessment Resources; 1996.

92. Reitan RM. The relation of the Trail Making Test to organic brain damage. J Consult Psychol. 1955.

93. Oosterman JM, Vogels RLCC, Van Harten B, Gouw AA, Poggesi A, Scheltens P, et al. Assessing mental flexibility: neuroanatomical and neuropsychological correlates of the trail making test in elderly people. Clin Neuropsychol. 2010 Feb;24(2):203-19.

94. Mohapatra B, Marshall RS. Performance differences between aphasia and healthy aging on an executive function test battery. Int J Speech Lang Pathol. 2019 Dec;1:1-11.

95. Feeney J, O'Sullivan M, Kenny RA, Robertson IH. Change in perceived stress and 2-year change in cognitive function among older adults: The Irish Longitudinal Study on Ageing. Stress Heal. 2018 Aug 1;34(3):403-10.

96. Wallace RB, Herzog AR. Overview of the Health Measures in the Health and Retirement Study. J Hum Resour. 1995;30:84.

97. Buschke H, Fuld PA. Evaluating storage, retention, and retrieval in disordered memory and learning. Neurology. 1974 Nov 1;24(11):1019-25.

98. Fischl B FreeSurfer. Vol. 62, Neurolmage. Neuroimage; 2012. p. 774-81.

99. Carey D, Nolan H, Kenny RA, Meaney J. Cortical covariance networks in ageing: Cross-sectional data from the Irish Longitudinal Study on Ageing (TILDA). Neuropsychologia. 2019 Jan;1:122:51-61.

100. Desikan RS, Ségonne F, Fischl B, Quinn BT, Dickerson BC, Blacker D, et al. An automated labeling system for subdividing the human cerebral cortex on MRI scans into gyral based regions of interest. 
Neuroimage. 2006 Jul 1;31(3):968-80.

101. Casaletto KB, Rentería MA, Pa J, Tom SE, Harrati A, Armstrong NM, et al. Late-life physical and cognitive activities independently contribute to brain and cognitive resilience. J Alzheimer's Dis. 2020 Jan 1;74(1):363-76.

102. Groot C, van Loenhoud AC, Barkhof F, Van Berckel BNM, Koene T, Teunissen CC, et al. Differential effects of cognitive reserve and brain reserve on cognition in Alzheimer disease. Neurology. 2018 Jan 9;90(2):e149-56.

103. Resende E, de PF, Rosen HJ, Chiang K, Staffaroni AM, Allen I, Grinberg LT, et al. Primary School Education May Be Sufficient to Moderate a Memory-Hippocampal Relationship. Front Aging Neurosci. 2018 Nov;20:10:381.

104. Belleville S, Mellah S, Cloutier S, Dang-Vu TT, Duchesne S, Maltezos S, et al. Neural correlates of resilience to the effects of hippocampal atrophy on memory. Neurolmage Clin. 2021 Jan 1;29:102526.

105. Lee DH, Lee P, Seo SW, Roh JH, Oh M, Oh JS, et al. Neural substrates of cognitive reserve in Alzheimer's disease spectrum and normal aging. Neuroimage. 2019 Feb 1;186:690-702.

106. Seabold S, Perktold J. Statsmodels: Econometric and Statistical Modeling with Python. In: Proceedings of the 9th Python in Science Conference. 2010.

107. Clewett DV, Lee TH, Greening S, Ponzio A, Margalit E, Mather M. Neuromelanin marks the spot: identifying a locus coeruleus biomarker of cognitive reserve in healthy aging. Neurobiol Aging. 2016 Jan 1;37:117-26.

108. Laubach M, Lammers F, Zacharias N, Feinkohl I, Pischon T, Borchers F, et al. Size matters: Grey matter brain reserve predicts executive functioning in the elderly. Neuropsychologia. 2018 Oct 1;119:172-81.

109. Manly JJ, Byrd DA, Touradji P, Stern Y. Acculturation, reading level, and neuropsychological test performance among African American elders. Appl Neuropsychol. 2004;11(1):37-46.

110. Manly JJ, Schupf N, Tang M-X, Stern Y. Cognitive decline and literacy among ethnically diverse elders. J Geriatr Psychiatry Neurol. 2005 Dec;29(4):213-7. 18(.

111. Pettigrew C, Soldan A, Li S, Lu Y, Wang MC, Selnes OA, et al. Relationship of cognitive reserve and APOE status to the emergence of clinical symptoms in preclinical Alzheimer's disease. Cogn Neurosci. 2013 Dec;4(3-4):136-42.

112. Manly JJ, Jacobs DM, Touradji P, Small SA, Stern Y. Reading level attenuates differences in neuropsychological test performance between African American and White elders. J Int Neuropsychol Soc. 2002;8(3):341-8.

113. Chin AL, Negash S, Xie S, Arnold SE, Hamilton R. Quality, and not just quantity, of education accounts for differences in psychometric performance between African Americans and white non-hispanics with Alzheimer's disease. J Int Neuropsychol Soc. 2012;18(2):277-85.

114. Ehrenberg RG, Brewer DJ, Gamoran A, Willms JD. Class Size and Student Achievement. Psychol Sci Public Interest. 2001 May;8(1):1-30. 2(. 
115. Hsieh TL. Motivation matters? The relationship among different types of learning motivation, engagement behaviors and learning outcomes of undergraduate students in Taiwan. High Educ. 2014 Sep 1;68(3):417-33.

116. Anatürk M, Suri S, Smith S, Ebmeier K, Sexton C. Mid-life and late life activities and their relationship with MRI measures of brain structure and functional connectivity in the UK Biobank cohort. bioRxiv. 2020 Apr 10;2020.04.10.035451.

117. Peeters G, Kenny RA, Lawlor B. Late life education and cognitive function in older adults. Int J Geriatr Psychiatry. 2020 Feb 19;gps.5281.

118. Deary IJ, Starr JM, MacLennan WJ. Is age kinder to the initially more able?: Differential ageing of a verbal ability in the healthy old people in Edinburgh study. Intelligence. 1998 Nov;26(4)(1):357-75.

119. McHutchison CA, Chappell FM, Makin S, Shuler K, Wardlaw JM, Cvoro V. Stability of Estimated Premorbid Cognitive Ability over Time after Minor Stroke and Its Relationship with Post-Stroke Cognitive Ability. Brain Sci. 2019 May 22;9(5):117.

120. Giambra LM, Arenberg D, Zonderman AB, Kawas C, Costa PT. Adult Life Span Changes in Immediate Visual Memory and Verbal Intelligence. Psychol Aging. 1995;10(1):123-39.

121. Staff RT, Murray AD, Deary IJ, Whalley LJ. What provides cerebral reserve? Vol 127, Brain. Oxford Academic; 2004. pp. 1191-9.

122. Crowe M, Andel R, Pedersen NL, Johansson B, Gatz M. Does participation in leisure activities lead to reduced risk of Alzheimer's disease? A prospective study of Swedish twins. Journals Gerontol - Ser B Psychol Sci Soc Sci. 2003 Sep 1;58(5):P249-55.

123. Sommerlad A, Sabia S, Livingston G, Kivimäki M, Lewis G, Singh-Manoux A. Leisure activity participation and risk of dementia: An 18-year follow-up of the Whitehall II Study. Vol. 95, Neurology. NLM (Medline); 2020. p. e2803-15.

124. Chan D, Shafto M, Kievit R, Matthews F, Spink M, Valenzuela M, et al. Lifestyle activities in mid-life contribute to cognitive reserve in late-life, independent of education, occupation, and late-life activities. Neurobiol Aging. 2018 Oct 1;70:180-3.

125. Park S, Choi B, Choi C, Kang JM, Lee JY. Relationship between education, leisure activities, and cognitive functions in older adults. Aging Ment Heal. 2019 Dec 2;23(12):1651-60.

126. Lipnicki DM, Makkar SR, Crawford JD, Thalamuthu A, Kochan NA, Lima-Costa MF, et al. Determinants of cognitive performance and decline in 20 diverse ethno-regional groups: A COSMIC collaboration cohort study. PLoS Med. 2019 Jul 1;16(7):12.

127. Tsai HJ, Chang FK. Associations of exercise, nutritional status, and smoking with cognitive decline among older adults in Taiwan: Results of a longitudinal population-based study. Arch Gerontol Geriatr. 2019 May;1:82:133-8.

128. Nilsson J, Lövdén M. Naming is not explaining: future directions for the cognitive reserve and brain maintenance theories. Alzheimers Res Ther. 2018 Apr 2;10(1):34.

129. Cheng ST. Cognitive Reserve and the Prevention of Dementia: the Role of Physical and Cognitive Activities. Vol. 18, Current Psychiatry Reports. Current Medicine Group LLC 1; 2016. 
130. Weinstein AM, Voss MW, Prakash RS, Chaddock L, Szabo A, White SM, et al. The association between aerobic fitness and executive function is mediated by prefrontal cortex volume. Brain Behav Immun. 2012 Jul;26(5):811-9.

131. Steffener J, Habeck C, O'Shea D, Razlighi Q, Bherer L, Stern Y. Differences between chronological and brain age are related to education and self-reported physical activity. Neurobiol Aging. 2016 Apr;40:138-44.

132. Habeck C, Razlighi Q, Gazes Y, Barulli D, Steffener J, Stern Y. Cognitive Reserve and Brain Maintenance: Orthogonal Concepts in Theory and Practice. Cereb Cortex. 2017 Aug;11(8):3962-9. 27 .

133. Stern Y, Mackay-Brandt A, Lee S, McKinley P, McIntyre K, Razlighi Q, et al. Effect of aerobic exercise on cognition in younger adults: A randomized clinical trial. Neurology. 2019 Feb;26(9):E905-16. 92(.

134. Arenaza-Urquijo EM, de Flores R, Gonneaud J, Wirth M, Ourry V, Callewaert W, et al. Distinct effects of late adulthood cognitive and physical activities on gray matter volume. Brain Imaging Behav. 2017 Apr 1;11(2):346-56.

135. Erickson KI, Leckie RL, Weinstein AM. Physical activity, fitness, and gray matter volume. Vol. 35: Neurobiology of Aging. Elsevier Inc.; 2014.

136. Vuoksimaa E, Panizzon MS, Chen CH, Eyler LT, Fennema-Notestine C, Fiecas MJA, et al. Cognitive reserve moderates the association between hippocampal volume and episodic memory in middle age. Neuropsychologia. 2013 May 1;51(6):1124-31.

137. McClelland GH, Judd CM. Statistical difficulties of detecting interactions and moderator effects. Psychol Bull. 1993;114(2):376-90.

138. Aguinis $\mathrm{H}$, Stone-Romero EF. Methodological artifacts in moderated multiple regression and their effects on statistical power. J Appl Psychol. 1997;82(1):192-205.

139. Bennett DA, Schneider JA, Tang Y, Arnold SE, Wilson RS. The effect of social networks on the relation between Alzheimer's disease pathology and level of cognitive function in old people: a longitudinal cohort study. Lancet Neurol. 2006 May;5(5):406-12.

140. Dufouil C, Alpérovitch A, Tzourio C, Dufouil C, Alpérovitch A. CT. Influence of education on the relationship between white matter lesions and cognition. Neurology. 2003 Mar;11(5):831-6. 60(.

141. Zahodne LB, Mayeda ER, Hohman TJ, Fletcher E, Racine AM, Gavett B, et al. The role of education in a vascular pathway to episodic memory: brain maintenance or cognitive reserve? Neurobiol Aging. 2019 Dec 1;84:109-18.

142. Joannette M, Bocti C, Dupont PS, Lavallée MM, Nikelski J, Vallet GT, et al. Education as a Moderator of the Relationship Between Episodic Memory and Amyloid Load in Normal Aging. Journals Gerontol Ser A. 2019 Oct 23;75(10):1820-6.

143. Rentz DM, Mormino EC, Papp KV, Betensky RA, Sperling RA, Johnson KA. Cognitive resilience in clinical and preclinical Alzheimer's disease: the Association of Amyloid and Tau Burden on cognitive performance. Brain Imaging Behav. 2017 Apr 1;11(2):383-90. 


\section{Abbreviations}

AD: Alzheimer's disease; AMNART: American National Adult Reading Test; CR: Cognitive Reserve; CR/RANN: The Cognitive Reserve/Reference Ability Neural Network Study; CTT: Color Trails Test; DOT: Dictionary of Occupational Titles; FOV: Field of view; GM: Grey matter; IPAQ-SF: International Physical Activity Questionnaire - Short Form; MCl: Mild cognitive impairment; MRI: Magnetic resonance imaging; MPRAGE: Magnetization-prepared rapid acquisition with gradient echo; NART: National Adult Reading Test; ROI: Regions of interest; TILDA: The Irish Longitudinal Study on Ageing; TMT: Trail Making Test; TR/TE: Repetition time/Echo time; WM: White matter.

\section{Figures}

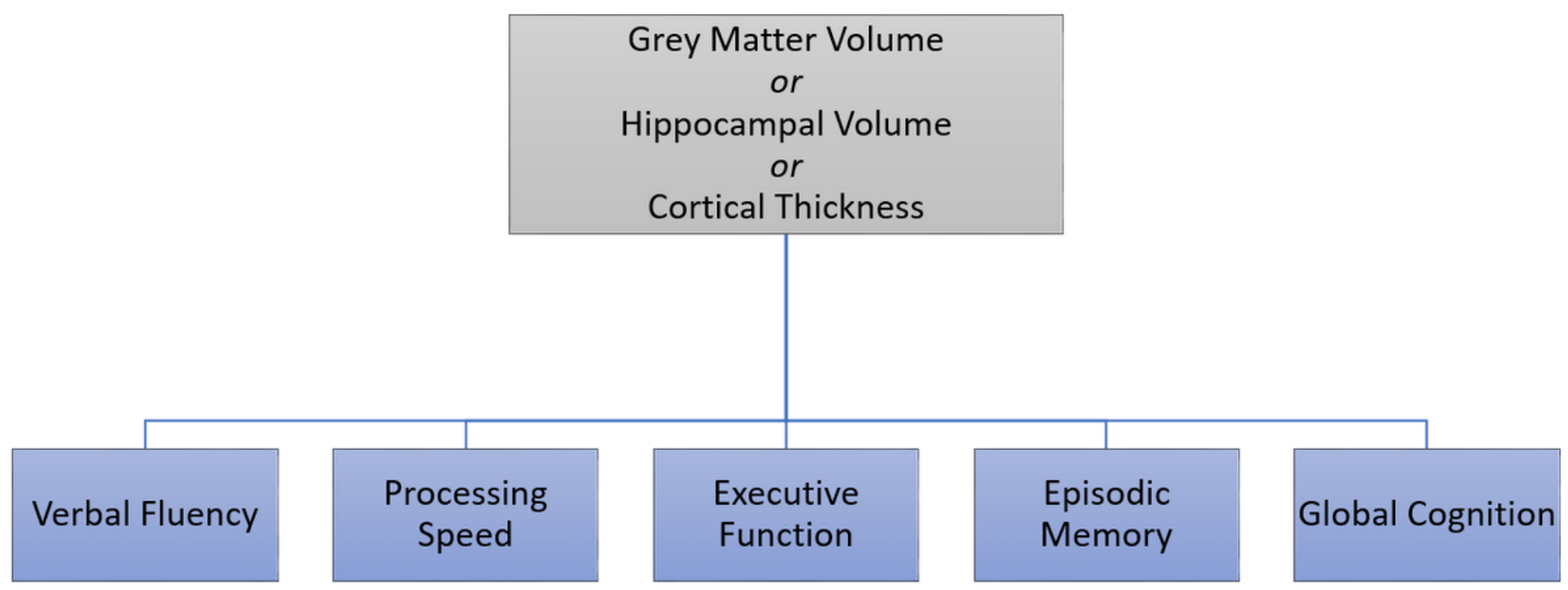

\section{Figure 1}

Schematic of basic brain structure-cognitive function models created for analysis. 


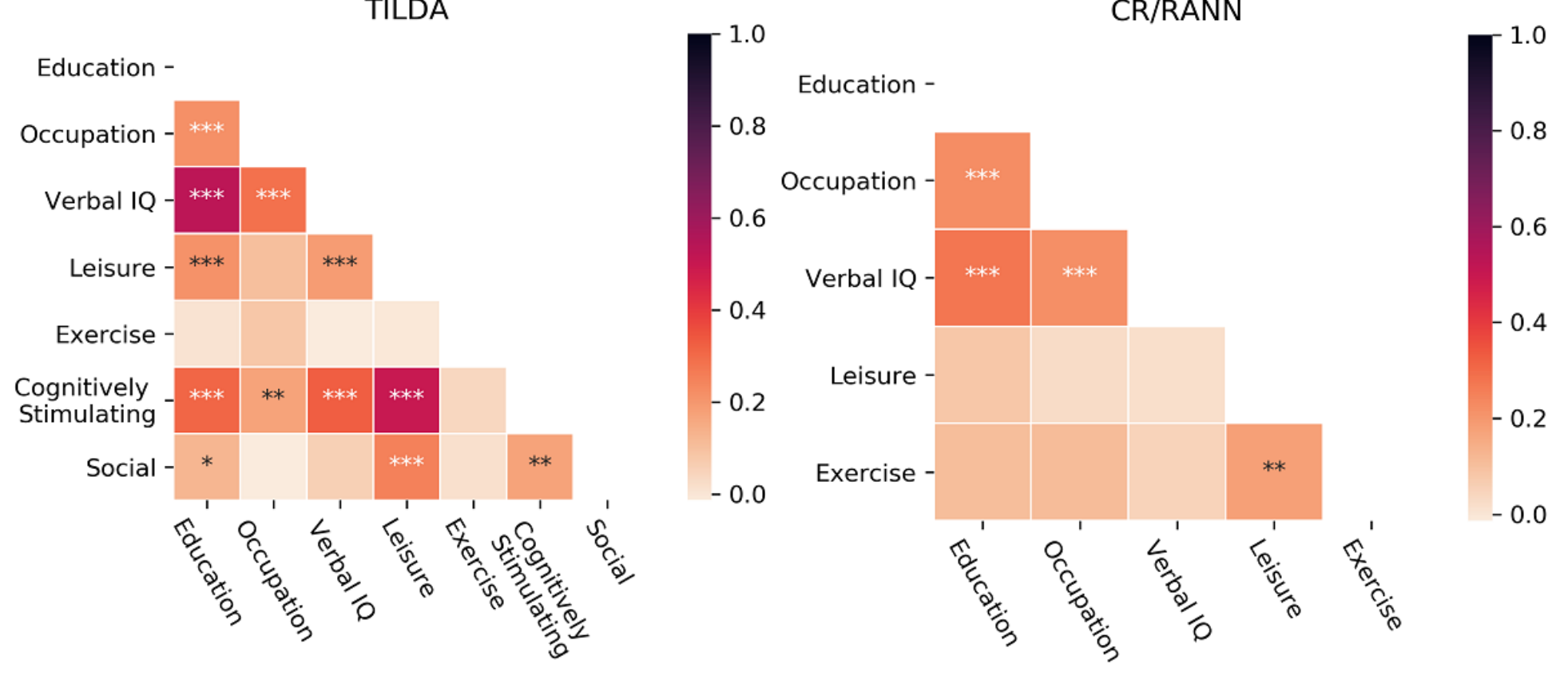

\section{Figure 2}

Heatmaps showing Pearson's correlations between individual proxies in each dataset. * $=p<.05,{ }^{\star \star}=p<$ $.01, * * *=p<.001$.

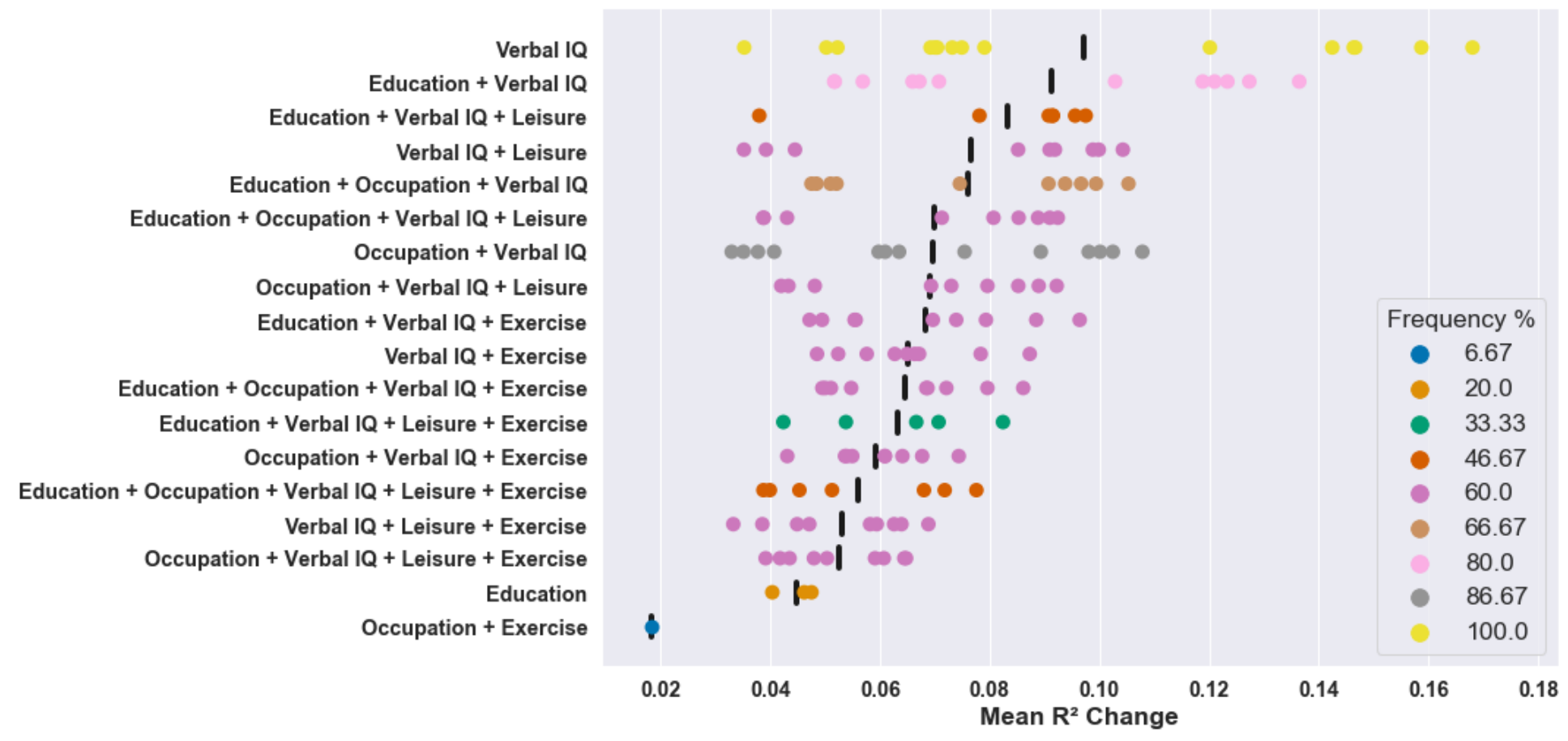

\section{Figure 3}

Mean R2 change across datasets in all models for proxies with significant effects. + indicate composite proxies (e.g. Education + Verbal IQ = composite of educational attainment and verbal intelligence). Black vertical bars represent the mean of significant R2 change values across all models for that proxy. All models were adjusted for brain structure, age, and sex. 


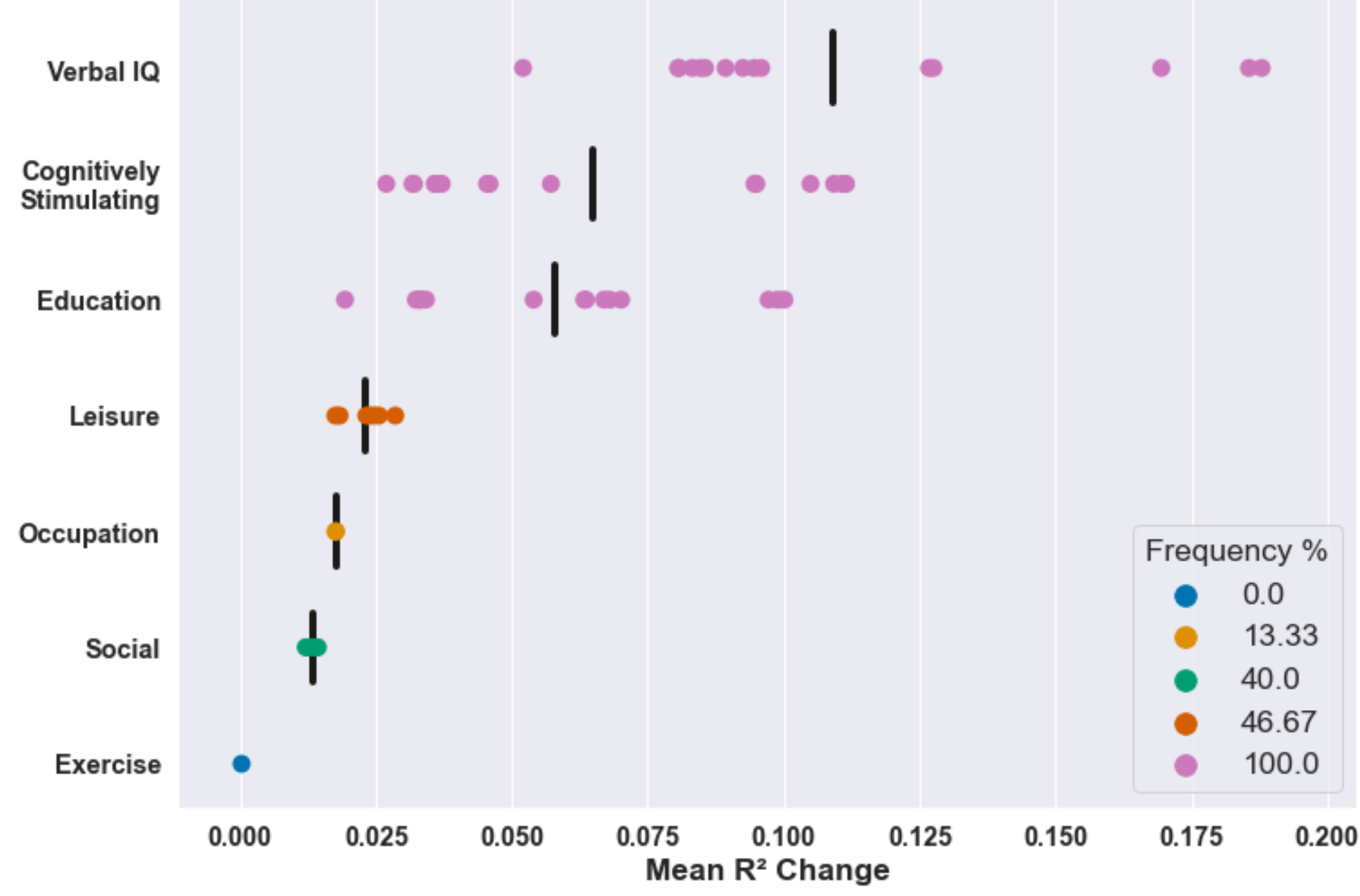

Figure 4

Mean R2 change in all TILDA models for individual proxies with significant effects. Black vertical bars represent the mean of significant R2 change values across all models for that proxy. All models were adjusted for brain structure, age, and sex. 


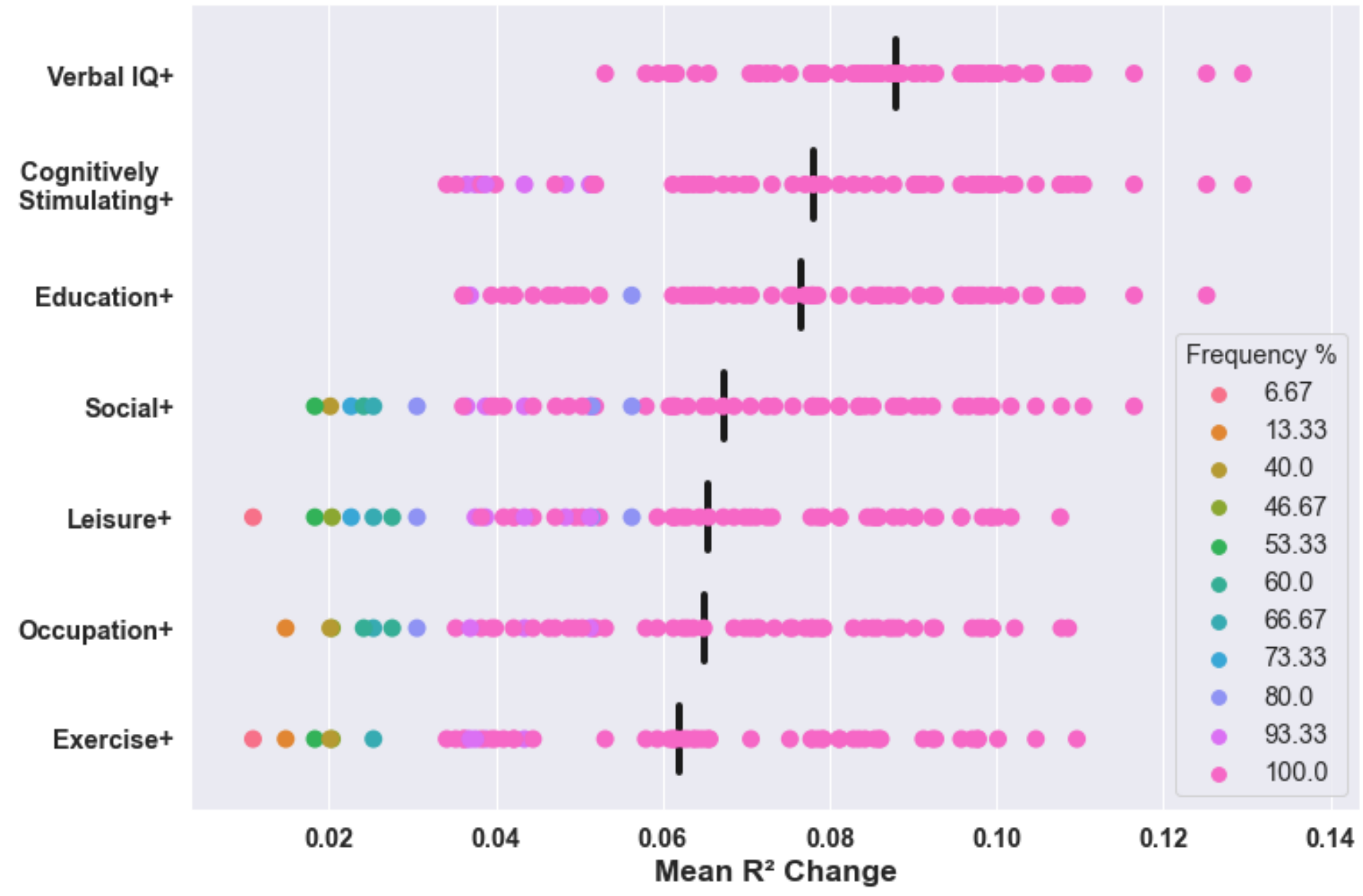

\section{Figure 5}

Mean R2 change in all TILDA models for composites proxies with significant effects. Each row refers to all composites including that proxy (e.g. Verbal IQ+ refers to all composites including verbal intelligence). Black vertical bars represent the mean of significant R2 change values across all models for all composites containing that proxy. All models were adjusted for brain structure, age, and sex.

\section{Supplementary Files}

This is a list of supplementary files associated with this preprint. Click to download.

- AdditionalFile1.xlsx

- AdditionalFile2.xIsx

- AdditionalFile3.xlsx

- AdditionalFile4.docx 